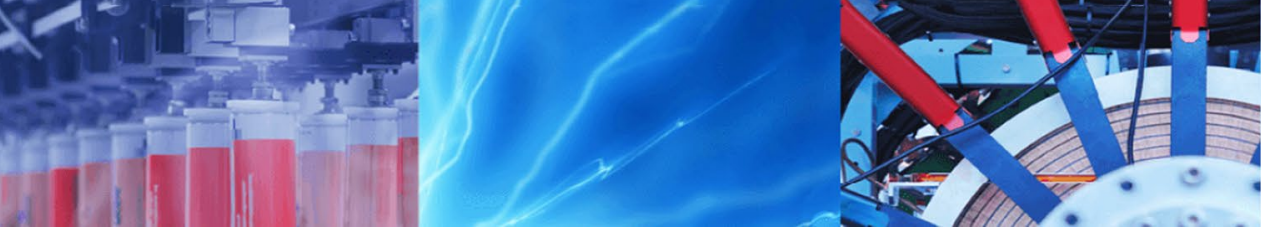

Research Article

\title{
Effects of geometrical and operational parameters on heat transfer and fluid flow of three various water based nanofluids in a shell and coil tube heat exchanger
}

\author{
Mohammad Zaboli $^{1} \cdot$ Seyed Soheil Mousavi Ajarostaghi ${ }^{2} \cdot$ Mehdi Noorbakhsh $^{1} \cdot$ Mojtaba Aghajani Delavar $^{2}$
}

(c) Springer Nature Switzerland AG 2019

\begin{abstract}
Heating and cooling of a system by heat exchanger Plays an important role in various industries. Improvement of heat transfer in heat exchangers resulted in reducing the size of heat exchanger, and utilizing more compressed heat exchangers with higher efficiency. Using helical/spiral tube is a passive method for improving the performance of heat exchangers due to its low geometry and high heat transfer coefficient. Also, in heat exchangers, one of the most important methods is additives such nanoparticles for liquids and classified as a passive method which does not need any external power like in active methods. The objective of this study is to investigate efficient operational and geometrical parameters. The considered geometrical parameters include helix pitch, coil diameter, and helix height. Also, the effect of using $\mathrm{Al}_{2} \mathrm{O}_{3}$, $\mathrm{CuO}, \mathrm{SiO}_{2}$ nanofluids on thermal performance of the heat exchanger is investigated numerically. The results show that the geometric parameters of the coil have a significant effect on the heat exchangers of the shell and coil.
\end{abstract}

Keywords Shell and coil heat exchanger $\cdot$ Helical coil $\cdot$ Heat transfer $\cdot$ Nanofluid $\cdot$ Thermal performance

\section{Introduction}

The heat exchangers are industrial equipment that can be used to heat or cool a fluid because of an indirect contact between two fluids inside them. This definition implies that in a heat exchanger there are at least two fluids in which the heat transfers between them. Heat exchangers are used widely in several industries, such as power plants, refineries, glass and metal melting industries, pharmaceutical and food industries, paper industry, petrochemicals, cold stores, gases condensation (such as air) and electronic industries. In the following, some explanations are given about different types of heat exchangers, the principles of heat transfer in them, and helical coil heat exchangers.

The classification of heat exchangers is based on contact area between hot and cold fluids, direction of cold and hot fluid flows, mechanism of heat transfer between hot and cold fluids, and mechanical structure of heat exchangers. Heat exchangers can be divided into two heat exchangers according to their structure: plate heat exchanger, and coil heat exchanger. Shell and coil heat exchanger is a type of coil heat exchanger. These heat exchangers consist of helical coils placed in a shell and these coils are also used in refrigeration systems in the form of concentric condensers and vaporizers. The heat transfer coefficient of helical coil is higher than straight tube. These heat exchangers are befitting for thermal expansion and clean fluids because cleaning them is almost impractical.

Studies in the field of heat transfer in helical coils are numerically and experimentally. In general, less experimental studies have been done due to complexity of heat transfer in helical coils. Most investigations are limited to

$\triangle$ Seyed Soheil Mousavi Ajarostaghi, s.s.mousavi@stu.nit.ac.ir; Mohammad Zaboli, mohammad.zaboli@ustmb.ac.ir; Mehdi Noorbakhsh, mehdi.noorbakhsh@ustmb.ac.ir; Mojtaba Aghajani Delavar, m.a.delavar@nit.ac.ir|'Department of Mechanical Engineering, Mazandaran University of Science and Technology, Babol, Iran. ${ }^{2}$ Department of Mechanical Engineering, Babol Noshirvani University of Technology, Babol, Iran.

SN Applied Sciences (2019) 1:1387| https://doi.org/10.1007/s42452-019-1431-2

Received: 26 July 2019 / Accepted: 9 October 2019 / Published online: 12 October 2019 
boundary conditions of constant wall temperature and constant heat flux on the wall. The constant temperature of wall is an ideal boundary condition in heat exchangers associated with phase shift at outlet of coil as well as constant heat flux on wall is a suitable boundary condition for coils that are under electric heating or under the influence of heat from nuclear fuel. Despite the fact that in many practical applications transferring heat between fluids is carried out without changing the phase, investigations on helical coils have been done under various boundary conditions.

Kumar et al. [1] studied helical double pipe heat exchangers numerically and experimentally. In a numerical approach, Ansys Fluent software was used in which standard $K-\varepsilon$ method applied for modeling turbulent flow and finally, profiles of velocity and temperature were demonstrated. In an experimental approach, using inlet and outlet temperature measurements and Wilson plot method, Figure $s$ of changes in the total heat transfer coefficient, as well as internal and external Nusselt numbers based on Dean Number are examined. They also reported an increase in total heat transfer coefficient by increasing Dean Number in inner coil with a constant mass flow in shell. A similar trend was observed in increasing total heat transfer coefficient by increasing Dean Number in outer tube, with a constant mass flow in tube.

Salimpour [2,3] studied helical shell and coil heat exchanger experimentally. Since change in temperature of heat exchanger will change the properties of fluid, it will also affect heat transfer coefficient. Salimpour evaluated the viscosity, thermal conductivity, specific capacity and density, by considering working fluid in the tube (oil) as a function of temperature. At an inlet fluid temperature of $70^{\circ} \mathrm{C}$, the Prandtl number is placed at an interval of Dravid et al. [4] correlation and the results of this study (variable properties) were compared with the results of Dravid et al. (constant properties). In high Dean Numbers, the assumption of constant properties led to a large difference in the results, and finally, a relevance for calculating the heat transfer coefficient of tube with variable properties was presented. They examined experimentally heat exchanger in two different conditions of counter flow and parallel flow. Salimpour by using 72 tests, presented a relevance for calculating the heat transfer coefficient of shell and coil tube separately and eventually, compared the proposed correlation with the others under different boundary conditions.

Jayakumar et al. [5] checked heat transfer in helical coils with boundary condition of constant temperature and constant heat flux in the wall. The results indicated that helix pitch is effective only in the developing area, and local Nusselt number is dependent on helix pitch when torsion is occurred in the flow. It is worth mentioning that average Nusselt number does not depend on the helix pitch. Thus, the Nusselt number depends only on coil diameter. In addition, they provided a correlation for calculating Nusselt number according to their boundary conditions. The results of the proposed correlations are the same in Reynolds numbers over 50,000. In another study, Jayakumar [6] studied helical shell and coil heat exchanger experimentally and numerically and presented a correlation for calculating heat transfer coefficient in tube.

Hashemi and Behabadi [7] studied nanofluid flow inside the helical coil under constant heat flux boundary condition. In this experimental study, they used cuo nanofluid with the weight percentages of $0.5,1$ and $2 \%$. The experimental system designed by them is as follows. The geometry of heat exchanger kept constant during the experiment, while heat flux of the outer wall of the tube, flow rate and nanofluid weight percentage have been changed. Based on the tests, they concluded that the effect of using nanofluid in helical coils with a constant flow rate is far greater than that in a smooth pipe. In 1995, Choi [8] for the first time introduced nanofluid as a new environment for heat transfer at Argonne National Laboratory. Nanofluids obtained by suspending nanoparticles within ordinary and commonly used heat transfer fluids, which are known as basic fluids.

Sheikholeslami et al. [9] studied the heat recovery and the use of latent heat energy storage systems (LHTESS). The effects of both inorganic nanoparticles as an additive for PCM (phase change materials) and magnetic field on the strength of PCM inside a porous energy storage system are modeled. For this purpose, a mixture of $\mathrm{CuO}$ nanoparticles and water was used and an external magnetic field was applied to the system. The influence of various parameters such as Lorentz strength, copper concentration/water content and the number of rails during charging have been investigated [10]. The solidification process has accelerated by adding copper nanoparticles to the pure PCM, according to the study. As the number of insulators increases, the average temperature increases and the total energy profiles decrease as the solid fraction profile increases [11].

Hardik et al. [12] consequence the effect of helical coil curvature on Reynolds number, Prandtl number, friction coefficient, and Nusselt number. In this study, water was used as a working fluid. Murshed et al. [13] have studied that addition of copper dioxide nanoparticles in water at a volume concentration of $0.5 \%$.

Wen and Ding [14] observed a high heat transfer coefficient in the laminar nanofluid flow, based on the calculations performed on experimental data. Yang and Ebadian [15] investigated a turbulent flow of a helical coil with finite length, numerically. The consequences showed that by increasing helix pitch, temperature distribution in 
vertical section is asymmetric and effect of helix pitch is intensified by increasing flow rate.

Sheikholeslami [16] investigated the forced convection studies of $\mathrm{CuO}-\mathrm{H}_{2} \mathrm{O}$ nanoparticles in a door-driven porous cavity affected by magnetic field. The effect of nanoparticle shape and Brownian motion on nanofluid properties have been considered. The solutions of the final equations are obtained by CVFEM. The graphs for different values of Darcy number (Da), CuO-H2O volume fraction (\%), Reynolds (RA) and Hartmann (ha) are shown. According to the results of the selection of nanoparticles, the platelet shape has the highest heat transfer rate. Total energy enhances with rise of amplitude [17].

Austen et al. [18] found that if curvature of a pipe is small, there is always a tendency to create critical velocity that is a characteristic of changing a laminar flow to turbulent flow. They observed the secondary flow for the first time by injecting acid into the water current in helical coils and u-tube pipes. They also observed the same trend by inserting sand into a turbulent flow. Jamshidi et al. [19] examined a helical shell and coil heat exchanger, experimentally and numerically. According to the outcome helix diameter, helix pitch and flow rate in the shell and tube can improve heat transfer in this type of heat exchanger.

Andrzejczyk et al. [20] presents a method for increasing the thermal penetration in the form of reflections to increase the heat energy efficiency of the coil shell. This paper successfully shows that it is possible to increase the efficiency of heat exchange in the coil of the heat exchanger shell using buffer ports. It has been shown in Tien that, due to the presence of curiosity, natural sesame has a significant effect on the values Little Reynolds and the great flame of heat. Configuration of the buffer and input also has a great impact on the results.

Hameed et al. [21] conducted an experimental and numerical study on the heat exchanger converter shell and splint. The spiral tube is made of Cu material. The fluid was working on both sides of the shell and the water pipe. Eight $\mathrm{K}$ type thermocouples have been installed at the inlet and outlet on each side and distributed over the length of the shell. To measure the flow rate of hot and cold water, two routers have been used. The key to this study was the coil volume and mass flow rate for both sides. Everywhere in the Earth, the Caleis Coil has changed. The consequences are compared with the case of 0 (direct tube). The consequences of this research show that the enhancement of the heat exchanger performance by reducing the spiral coil field due to the increase of secondary flow. Also, decreasing the mass flow increases the efficiency of the heat exchanger due to the increase in contact time.

KumarNaik et al. [22] investigated the heat transfer using three different non-Newton nanotubes including
$\mathrm{Fe}_{2} \mathrm{O}_{3}, \mathrm{Al}_{2} \mathrm{O}_{3}$, and $\mathrm{CuO}$ nanoparticles in the CMC carboxymethylcellulose fluid (CMC). Studies have been done to determine the increase of heat transfer in comparison with the base fluid (CMC blue solution) in the shell and the hydraulic coil heat exchanger. Non-Newtonian nanoparticles containing nanoparticles have been prepared in the range of $0.2-1.0 \mathrm{wt} \%$. Nanofluid and water were used respectively on the side of the tube and tube. Thermal analysis to determine the coefficient of total heat transfer and the number of shells in various mood, such as the flow rate of cold water, the temperature of the nanotube and the agitator speed in minutes. The consequences show that the Nusselt number increases with increasing nanofluide concentration, the temperature of the lateral fluid of the bottle, the number of religions (coil side flow velocity), and the agitator speed. According to the consequence, the consequence indicated that nanofiltration based on $\mathrm{CuO} /$ CMC provides more heat transfer than two other types of liquid $\left(\mathrm{Fe}_{2} \mathrm{O}_{3}\right.$ and $\left.\mathrm{Al}_{2} \mathrm{O}_{3}\right)$. The heat transfer function of the non-Newtonian nanofluids significantly increased in the higher nano-floid concentration, left-hand thermometer, stirrer speed and number of religions.

Sheikholeslami simulated the nanofluid flow in a threedimensional porous cavity by the magnetic field. The area is filled with $\mathrm{Al}_{2} \mathrm{O}_{3}-\mathrm{H}_{2} \mathrm{O}$ nanoparticles. Mesoscopic simulations were performed for different values of Darcy number, Hartmann number, and Reynolds number. The results showed that the temperature gradient is directly related to Darcy number and Reynolds number [23].Nanofluidic Properties, Viscosity of Nanofluid Changes with Brownian Motion Effects. The role of radiation, buoyancy and Hartmann number in alumina treatment has been shown. The results show that the effects of convection decrease with increasing magnetic forces. Radiation can reduce the temperature gradient [24].

Zare et al. [25] used Nanophile tubes and couplings as two passive ways to increase heat transfer. In this scrutiny, the current of turbulent CuO-water nanopilot in coiled and conical coils is numerically has been studied with a fixed wall temperature through a mixed specimen. Simulation results have been confirmed by using empirical data on the heat transfer coefficient and the drop in pressure of the spiral twisted tubes for the number of different Reynolds. They compared four different simulation geometries. The first tube was a twisted cone. Others were twisted tubes whose coil diameter was at least the maximum and average diameter of the coil coil winding. The profiles of the stronger secondary flow velocity in the cone coil pipe were indicated in a specific religion.

Taraprasad Mohapatra et al. [26] modeled three liquid heat exchangers analytically to forespeak the effects of different plan parameters on its thermal performance. The current heat exchanger is an improved heat exchanger for 
two pipes, where a silicon coil in the occupied space space is inserted between two straight pipes. This differs from the other three heat exchangers in terms of structure, flow regulation and thermal point, where hot water flows through a helium-coil coil as a heat-transfer fluid and continuously transfers heat to the water and the natural air is flowing, in the outer ring and the inner tube is straight. The consequence of the analytical approach are comparative and authoritative compared to the literature and have been wellmatched with them.

In the present study, the effects of efficient geometrical parameters on the thermal performance of the shell and coil tube heat exchanger are investigated numerically. The considered geometrical parameters are coil diameter $\left(\mathrm{d}_{\mathrm{C}}\right)$, pitch $\left(P_{C}\right)$ and height $(H)$. Also, the nanofluid is utilized as working fluid in the coil tube and different nanoparticle volume concentration including 2, 3, 4 and $5 \%$ are studied. It is worth mentioning that in all investigated models, the heat transfer area is kept constant. Accordingly, the helix diameter (Dc) is considered as free parameter.

The novelty of present work: The investigation includes of two section which at the first part, the effect of the geometry and at the second section, the effect of utilizing different water-based nanofluid on the thermal performance of the shell and coil tube heat exchanger are evaluated. In the first part, effects of efficient parameters are investigated by keeping constant the heat transfer area and using a free parameter. In all previous studies, the geometrical parameters have been investigated without focusing on keeping constant the heat transfer area. Obviously, by increasing and decreasing a geometrical parameter which leads to an increase in the heat transfer area, the heat transfer rate will be increased. But here, a comprehensive study is presented to investigate the effects of geometrical parameters (by keeping constant the heat transfer area) and to study the effect of using $\mathrm{Al}_{2} \mathrm{O}_{3}$, $\mathrm{CuO}, \mathrm{SiO}_{2}$-water nanofluid in comparison with the pure water on the thermal performance of the shell and coil tube heat exchanger.

\section{Governing Equations}

Single-phase equations include conservation equations for mass, momentum, and energy. The mass and momentum equations are used to calculate velocity vectors. The energy equation is used to calculate the temperature distribution and heat transfer coefficient. These equations are divided into three categories:

Continuity:The conservation equation for mass or continuity is as follows [27, 28]:

$\frac{\partial \rho}{\partial t}+\nabla \nabla \cdot(\rho \vec{v})=S_{m}$
The above equation is the general form of mass conservation equation and is valid in compressible and incompressible flows. The added mass to continuous phase of the second phase of diffusion is such as evaporation of liquid droplets or any other defined source.

Momentum:The conservation equation for momentum in each non-accelerating coordinate is defined as follows $[27,28]$ :

$\frac{\partial(\rho \vec{v})}{\partial t}+\nabla \cdot(\rho \vec{v} \vec{v})=-\nabla p+\nabla(\overline{\bar{\tau}})+\rho \vec{g}+\vec{F}$

In the above equation, $p$ is static pressure, $\overline{\bar{\tau}}$ is stress tensor, $\rho \vec{g}$ and $\vec{F}$ are the volumetric forces of gravity acceleration and external forces, respectively. The stress tensor is defined as $[27,28]$ :

$\overline{\bar{\tau}}=\mu\left[\left(\nabla \vec{v}+\nabla \vec{v}^{T}-\frac{2}{3} \nabla \cdot \vec{v} l\right)\right]$

In the above equation, $\mu$ is molecular viscosity and $I$ is the right term of the second-order tensor that is effect of volume change.

Energy:The ANSYS FLUENT 18.2 software solved the energy conservation equation as defined below $[27,28]$ :

$\frac{\partial(\rho E)}{\partial t}+\nabla \cdot(\vec{v}(\rho E+p))=\nabla\left(k_{\text {eff }} \nabla T-\sum_{j} h_{j} \vec{j}_{j}+\left(\overline{\bar{\tau}}_{\text {eff }} \cdot \vec{v}\right)\right)+S_{h}$

In the above equation, $K$ is thermal conductivity and $\vec{J}_{j}$ is diffusion flux of different species. The three terms in the right side of the upper equation are conduction, diffusion, and loss viscous, respectively. $S_{h}$ is heat generated by chemical reactions or any other volumetric heat source. The heat transfer coefficient, average Nusselt number and friction factor are defined as following [29-33]:

$h=\frac{\mathrm{q}^{\prime \prime}}{(\mathrm{Tb}-\mathrm{Tw})}$

$N u=\frac{h d}{k}$

$f=\frac{2 \cdot d h \cdot \Delta P}{\mathcal{P} \cdot u^{2} . I}$

The equations used for coefficient of performance are as follows [29-34]:

$\mathrm{COP}=\frac{\mathrm{Nu} / \mathrm{Nu} \text { 。 }}{\left(\mathrm{f} / \mathrm{f}_{\circ}\right)^{1 / 3}}$

As can be seen, coefficient of performance consists of parameters including Nusselt number, hydraulic diameter, inlet velocity, fluid density, and pressure drop. The equations 
used to calculate the length and area of helical coil are presented.

$I=\frac{H}{P_{c}} \sqrt{(3.148 D c)^{2}+P_{c}^{2}}$

$A=1 \pi d^{2} / 4$

It can be seen from the correlation between length and area of helical coil that length of helical coil depends on helix height, helix pitch, and helix diameter. Also, helical coil area depends on length of the helical coil and helix diameter.

For thermophisical properties of the nanofluid, following correlations are utilized here for numerical simulations [35-39]:

$\rho_{n f}=\left(\frac{m}{V}\right)_{n f}=\frac{m_{f}+m_{p}}{V_{f}+V_{p}}=\frac{\rho_{f} V_{f}+\rho_{p} V_{p}}{V_{f}+V_{p}}=(1-\phi) \rho_{f}+\phi \rho_{p}$

$\mathrm{cp}_{\mathrm{nf}}=\frac{(1-\phi)(\mathrm{pcp}) \mathrm{f}+\emptyset(\mathrm{pcp}) \mathrm{N}}{(1-\phi) \mathrm{p}_{\mathrm{f}}+\emptyset_{\mathrm{N}}}$

$\mathrm{K}_{n f}=1+4.4 \operatorname{Re}^{0.4} \cdot \operatorname{Pr}_{f}^{0.66} \cdot\left(\frac{\mathrm{T}}{\mathrm{T}_{\mathrm{fr}}}\right)^{10} \cdot\left(\frac{\mathrm{K}_{\mathrm{p}}}{\mathrm{K}_{\mathrm{f}}}\right)^{0.3}+\infty^{0.66} \cdot \mathrm{K}_{\mathrm{f}}$

$\mu_{n f}=(1+\infty)^{11.3} \cdot\left(1+\frac{\mathrm{T}}{70}\right)^{-0.038} \cdot\left(1+\frac{\mathrm{dpp}}{170}\right)^{-0.061} . \mu_{\mathrm{f}}$

It is worth mentioning that the critical Reynolds number of coil tube is calculated by the Schmidt [40] correlation which is defined as follows:

$R e_{c r}=2300\left[1+8.6(r / R c)^{0.45}\right]$
Table 1 Geometrical parameters of the considered shell and coil heat exchanger

\begin{tabular}{ll}
\hline Parameter & Value \\
\hline Shell length $\left(L_{s h}\right)$ & $700 \mathrm{~mm}$ \\
Shell diameter $\left(D_{s h}\right)$ & $620 \mathrm{~mm}$ \\
$\begin{array}{l}\text { Inlet and outlet diameter of the } \\
\text { shell }\left(d_{\text {sh }}\right)\end{array}$ & $50 \mathrm{~mm}$ \\
Coil diameter $\left(d_{c}\right)$ & $16 \mathrm{~mm}$ \\
Helix diameter $\left(D_{c}\right)$ & Free Parameter \\
Coil pitch $\left(P_{c}\right)$ & $40 \mathrm{~mm}, 60 \mathrm{~mm}, 90 \mathrm{~mm}, 120 \mathrm{~mm}$ \\
Height of spiral coil $(H)$ & $0.24 \mathrm{~m}, 0.3 \mathrm{~m}, 0.36 \mathrm{~m}, 0.42 \mathrm{~m}$ \\
Heat transfer area $(A)$ & $0.00097 \mathrm{~m}^{2}, 0.0012 \mathrm{~m}^{2}, 0.0016 \mathrm{~m}^{2}$ \\
\hline
\end{tabular}

where $r$ and $R_{c}$ are the radius of inner coil tube and the radius of the helical, respectively. The Eq. (15) is validated for $\left(\frac{1}{860}\right)<\left(\frac{r}{R_{c}}\right)$ which in this range, the critical Reynolds number of helical coil is equal to the critical Reynolds number of a simple straight tube. So, according to the Eq. (15) and the dimensions of studied geometry here, the flow regime is laminar present study. By calculating the critical Reynolds of the present study based on the dimensions of the studied coil here, the critical Reynolds in the present study is obtained 9100 which the maximum Reynolds number in the present study is 5270 . So, the fluid flow regime is considered laminar.

\section{Numerical domain and methods}

According to objective of this study that is to investigate heat transfer in a shell and coil heat exchanger, the geometry of considered heat exchanger is shown in Fig. 1. The

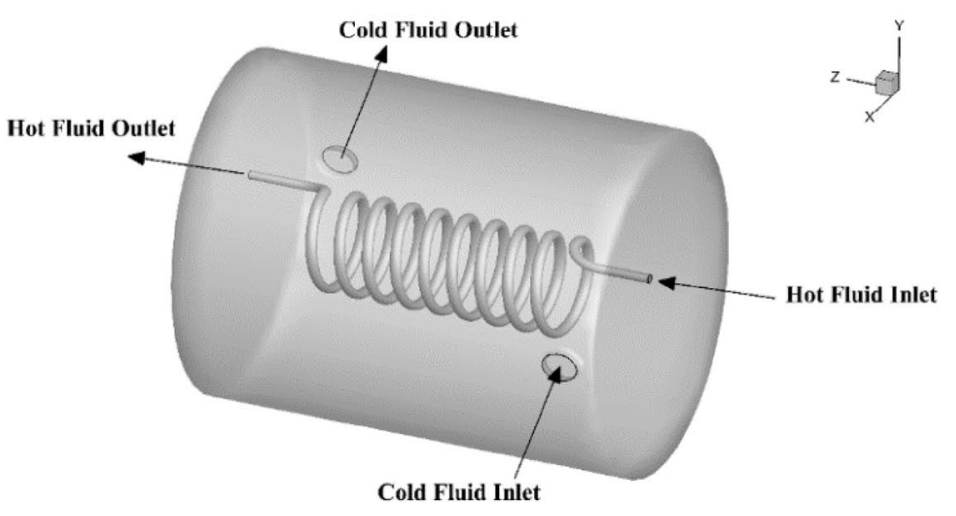

(a)

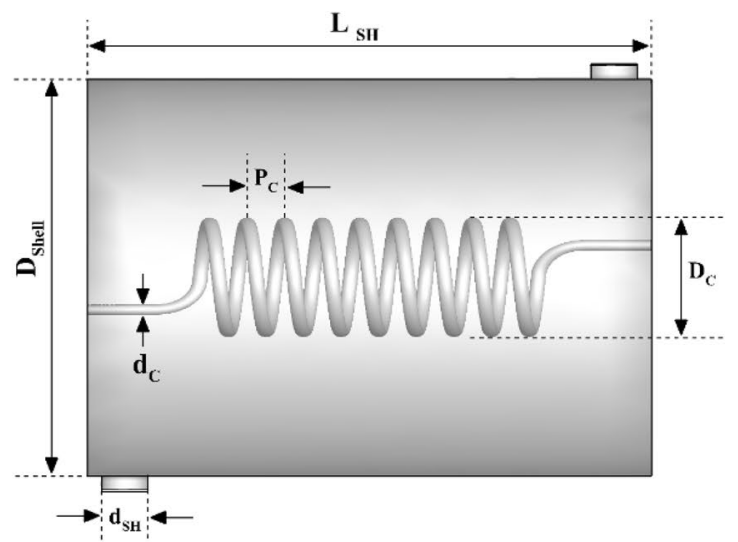

(b)

Fig. 1 a The geometry of the considered model and $\mathbf{b}$ the geometrical parameters of the investigated model 
values of different geometrical parameters are presented in Table 1.

The fluid flow in the tube as hot fluid is water which flows at a constant temperature of $50^{\circ} \mathrm{C}$ with four different velocities. The fluid flow in the shell as cold fluid is water that flows at a constant temperature of $20^{\circ} \mathrm{C}$ and a constant velocity of $0.008 \mathrm{~m} / \mathrm{s}$. The boundary conditions for the inlet and outlet sections of shell and tube are VELOCITY INLET and PRESSURE OUTLET, respectively. The other surfaces are considered as Wall. The inlet velocity is calculated by utilizing the volume flowrate. Four different volume flowrate, including 1, 2, 3, and 4 LPM are considered for the numerical simulations. Figure 2 shows the generated grids for considered geometries. The working fluid here is the pure water which the thermos physical properties of the pure water are listed in Table 2.

The problem is solved using the commercial software ANSYS Fluent 18.2 based on the finite volume method. The discretization of the mass, momentum, turbulence kinetic energy, turbulence dissipation rate and energy equations are performed by the second-order upwind scheme. The velocity-pressure coupling is overcome by the SIMPLE algorithm. The Green-Gauss cell-based method is employed to evaluate all gradients. The convergence criterion was fixed to $10^{-6}$ for the residuals of the continuity, momentum, turbulence kinetic energy and turbulence dissipation rate equations and $10^{-8}$ for the energy equation.
Table 2 Thermos physical properties of the pure water

\begin{tabular}{lll}
\hline Properties & & Value \\
\hline Density $\left(\mathrm{kg} / \mathrm{m}^{3}\right)$ & $\rho$ & 998.2 \\
Specific heat $(\mathrm{j} / \mathrm{kg} \mathrm{k})$ & $\mathrm{C}_{\mathrm{p}}$ & 4182 \\
Thermal conductivity $(\mathrm{w} / \mathrm{m} \mathrm{k})$ & $\mathrm{k}$ & 0.6 \\
Viscosity $(\mathrm{kg} / \mathrm{m} \mathrm{s})$ & $\mu$ & 0.001003 \\
\hline
\end{tabular}

\section{Results and discussion}

\subsection{Validation and grid independent studies}

In this section, results obtained by solving the governing equations for fluid flow in the shell and coil heat exchanger are obtained and compared with the experimental results. Validation of present numerical solution (using water) with experimental results [19] is conducted. The water is assumed to flow in both of helical coil and shell. A specific geometry with a helix pitch of $0.015 \mathrm{~m}$ and a helix diameter of $0.0813 \mathrm{~m}$ is considered here for validation study. The results of present numerical solution are compared with experimental results of Jamshidi et al. [19].

Figure 3 shows the comparison between the results obtained from numerical solution of present study and experimental results of Jamshidi et al. [19]. As it can be seen, the difference between results is minimum. To compare better the obtained results with the results of experimental study [19], the results are compared with together in Table 3. Accordingly, the maximum error is $6.6 \%$. So, the obtained results from the present numerical study have good agreement with the experimental results [19].
Fig. 2 Generated grid of studied shell and coil heat exchanger
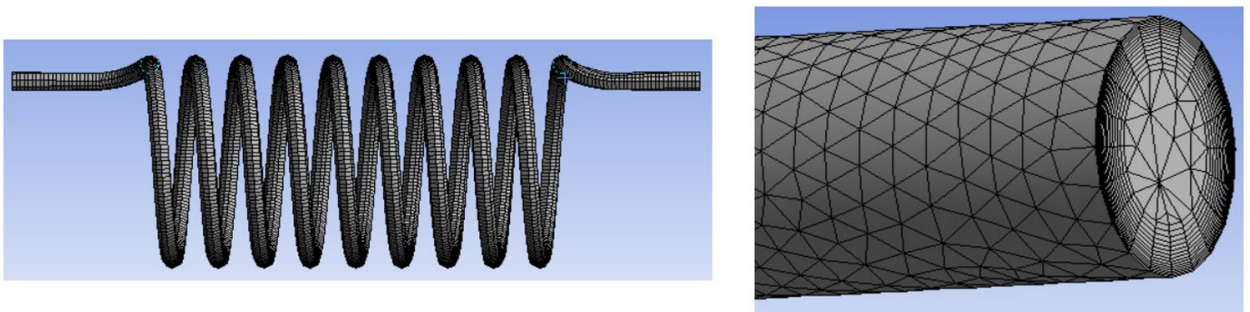

(a)
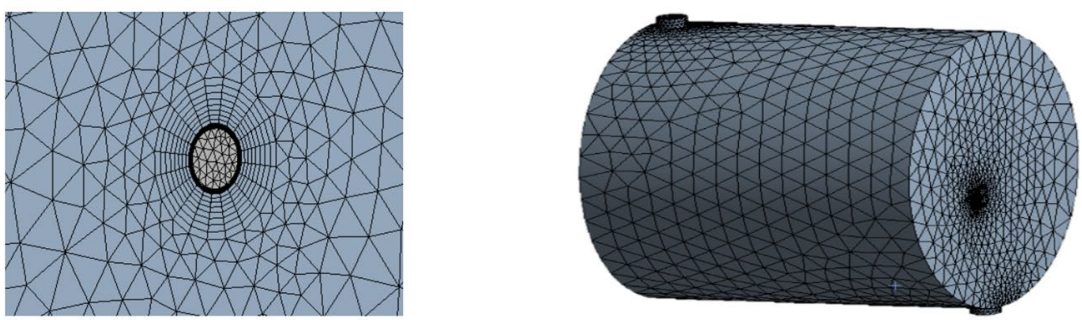

(b) 


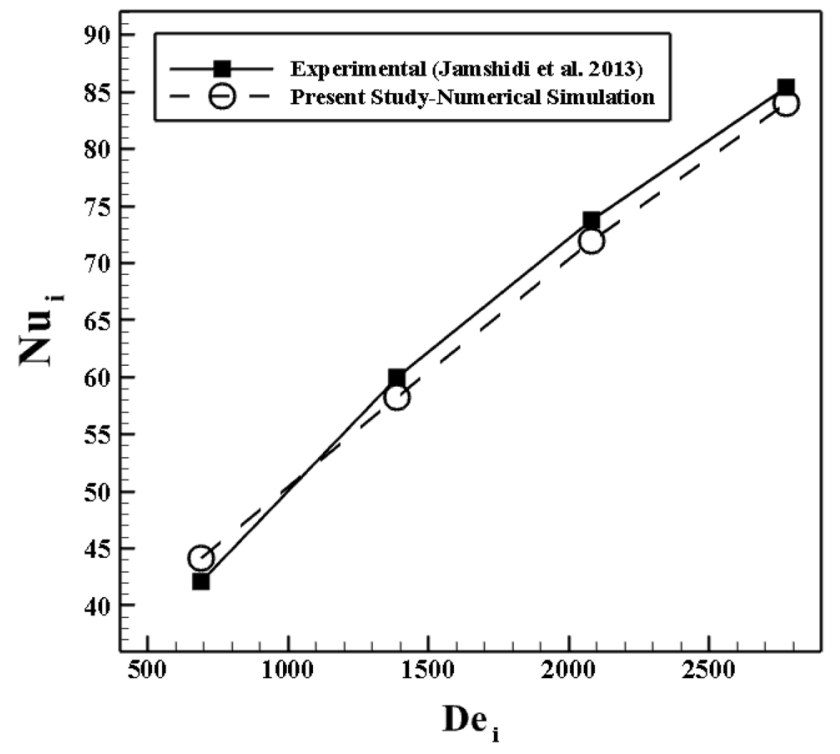

Fig. 3 Comparison of Nusselt number of tube side with experimental results of Jamshidi et al. [19]

Table 3 The difference between the present numerical results and the experimental results of Jamshidi et al. [19]

\begin{tabular}{llll}
\hline $\begin{array}{l}\text { Volume } \\
\text { flowrate } \\
(Q)\end{array}$ & $\begin{array}{l}\text { Experimental results } \\
\text { (Jamshidi et al. [19]) }\end{array}$ & $\begin{array}{l}\text { Present study } \\
\text { (numerical simula- } \\
\text { tion) }\end{array}$ & Error (\%) \\
\hline 1 LPM & 42.11 & 44.91 & 6.6 \\
2 LPM & 59.97 & 57.26 & 4.5 \\
3 LPM & 73.74 & 71.88 & 2.5 \\
4 LPM & 85.39 & 83.96 & 1.6 \\
\hline
\end{tabular}

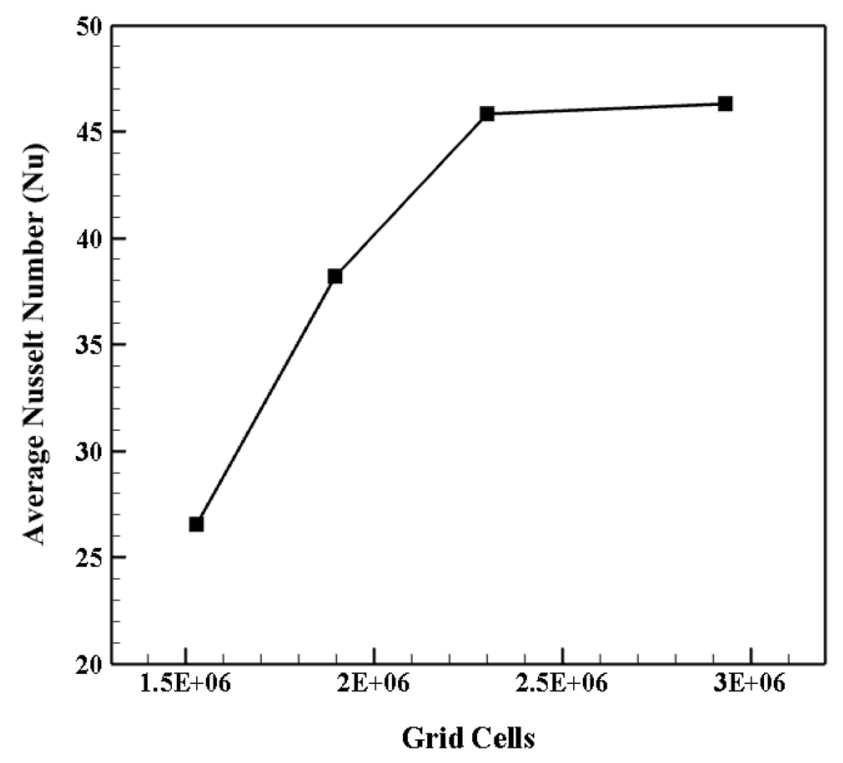

Fig. 4 Results of the grid independency study
In order to study the grid independency, four grids including 1,528,658, 1,896,552, 2,301,475, and 2,942,527 cells are considered. The results are illustrated in Fig. 4. Accordingly, it can be seen that the difference between the grids with $2,301,475$ and $2,942,527$ is very low. So, to save the cost and time of simulation, grid with 2,301,475 cells is selected for other simulations.

\subsection{Effect of efficient geometrical parameters}

In the following, in all considered models in the present study, heat transfer area is kept constant in each subsection. In order to keep constant the heat transfer area, helix diameter $\left(D_{C}\right.$ in Fig. 1 b) has been chosen as a free parameter in all geometries. The values of geometrical parameters for all investigated models are listed in Table 4. Generally, three different geometric parameters including coil pitch, diameter and height are studied numerically.

\subsubsection{Influence of coil pitch}

In this section, the effect of coil pitch on heat transfer is investigated numerically. Four different coil pitch, including $0.04,0.06,0.09$, and $0.12 \mathrm{~m}$ are considered here which are presented here as models (1-4), respectively. According to Table 4, from model (1-4), as the coil pitch increases, to keep constant the heat transfer area, the helix diameter increases, too. Here the heat transfer area is kept constant as $9 \times 10^{-4} \mathrm{~m}^{2}$. Here helix height $(H)$ and coil diameter $\left(d_{C}\right)$ are kept constant as $0.36 \mathrm{~m}$ and $0.016 \mathrm{~m}$, respectively.

Nusselt number versus various helix pitches for different volume flowrate is shown in Fig. 5 which shows that firstly, in all models, as the volume flowrate (or inlet velocity or Reynolds number) increases, because of the forced convection, the average Nusselt number (or heat transfer rate) rises. Also, it can be seen that as the coil pitch increases (from model 1 to 4), the average Nusselt number decreases. On the other hand, as the coil pitch increases, the better contact between the cold fluid and the coil containing the hot fluid occurs, and the temperature difference between the coil wall and the cold fluid decreases, which reduces the effect of convection heat transfer. The maximum and minimum average Nusselt number belong to model $1\left(P_{C}=0.04 \mathrm{~m}\right)$ at $\mathrm{Q}=4 \mathrm{LPM}$ and model 4 $\left(P_{C}=0.12 \mathrm{~m}\right)$ at $\mathrm{Q}=1 \mathrm{LPM}$.

In Fig. 6, contours of temperature are shown for two different models (coil pitches). As shown in Fig. 6 , by reducing helix pitch, curvature of coil increases and secondary flow improves the heat transfer in helical coil, as well as by increasing helix pitch a better contact between flow of tube and shell is created which results in increasing heat transfer between two fluids. On the other hand, as the coil pitch rises (model 1 to 4), to keep constant the heat 
Table 4 Parameters for considered model at various helix pitches

\begin{tabular}{|c|c|c|c|c|c|c|}
\hline \multirow[t]{2}{*}{ Model } & $\begin{array}{l}\text { Height of spiral } \\
\text { coil }\end{array}$ & Coil pitch & Helix diameter & Spiral coil length & Coil diameter & Heat transfer area \\
\hline & $H(\mathrm{~m})$ & $P_{\mathrm{c}}(\mathrm{m})$ & $D_{c}(\mathrm{~m})$ & $L(\mathrm{~m})$ & $d_{c}(\mathrm{~m})$ & $A\left(\mathrm{~m}^{2}\right)$ \\
\hline \multicolumn{7}{|c|}{ Effect of coil pitch } \\
\hline Model 1 & 0.36 & 0.04 & 0.17 & 4.829 & 0.016 & $9 \times 10^{-4}$ \\
\hline Model 2 & 0.36 & 0.06 & 0.24 & 4.547 & 0.016 & $9 \times 10^{-4}$ \\
\hline Model 3 & 0.36 & 0.09 & 0.36 & 4.547 & 0.016 & $9 \times 10^{-4}$ \\
\hline Model 4 & 0.36 & 0.12 & 0.48 & 4.547 & 0.016 & $9 \times 10^{-4}$ \\
\hline \multicolumn{7}{|c|}{ Effect of coil diameter } \\
\hline Model 5 & 0.36 & 0.09 & 0.48 & 6.05 & 0.016 & $1.2 \times 10^{-3}$ \\
\hline Model 6 & 0.36 & 0.09 & 0.39 & 4.92 & 0.018 & $1.2 \times 10^{-3}$ \\
\hline Model 7 & 0.36 & 0.09 & 0.32 & 4.04 & 0.02 & $1.2 \times 10^{-3}$ \\
\hline Model 8 & 0.36 & 0.09 & 0.25 & 3.16 & 0.022 & $1.2 \times 10^{-3}$ \\
\hline \multicolumn{7}{|c|}{ Effect of coil height } \\
\hline Model 9 & 0.24 & 0.04 & 0.43 & 8.12 & 0.016 & $1.6 \times 10^{-3}$ \\
\hline Model 10 & 0.3 & 0.04 & 0.35 & 8.26 & 0.016 & $1.6 \times 10^{-3}$ \\
\hline Model 11 & 0.36 & 0.04 & 0.29 & 8.22 & 0.016 & $1.6 \times 10^{-3}$ \\
\hline Model 12 & 0.42 & 0.04 & 0.25 & 8.27 & 0.016 & $1.6 \times 10^{-3}$ \\
\hline
\end{tabular}

Three different geometrical parameters including coil pitch, coil diameter and coil height are investigated numerically which are shown as models $(1-12)$ in the present study

Helix diameter $\left(D_{C}\right)$ is the free parameter which means that in order to keep constant the heat transfer area, by changing the main parameter (like coil pitch, coil diameter or coil height), the free parameter will be changed

In order to compare the models in each part, [models (1-4), models (5-8), models (9-12)], the heat transfer area is kept constant, separately

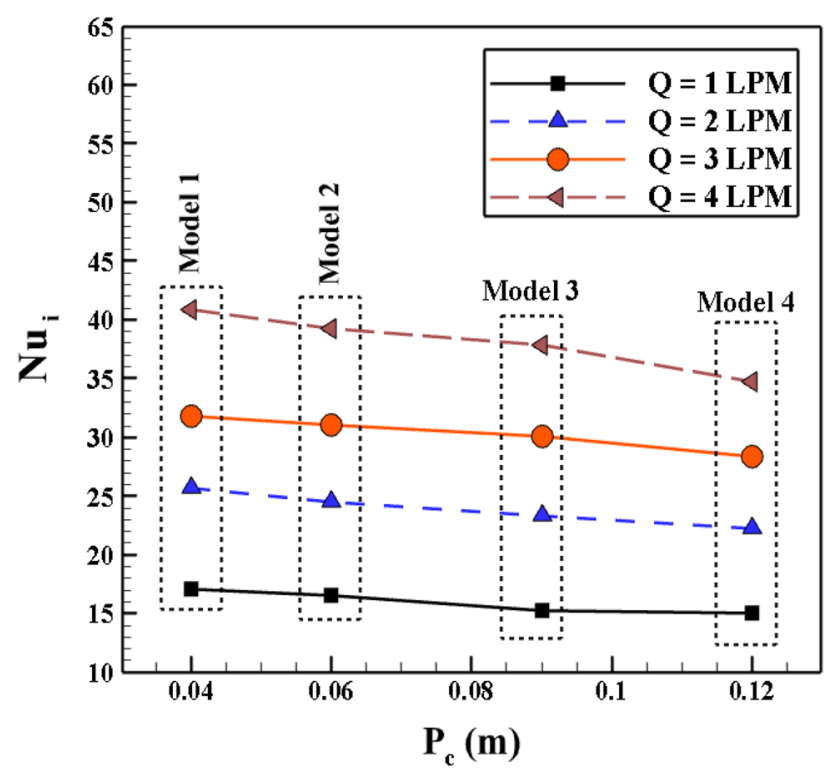

Fig. 5 Average Nusselt number versus the helix pitch for different volume flowrate of tube at $\mathrm{H}=0.36 \mathrm{~m}$ and $\mathrm{d}_{\mathrm{C}}=0.016 \mathrm{~m}$

transfer area, the helix diameter increases which leads to more contact between the coil the fluid in the shell. So, the temperature distribution in the shell of models 4 is more uniform than model 1. The variation of outlet temperature of hot fluid at various coil pitches is illustrated in Fig. 7.
According to Fig. 7, the higher flow through tube leads to the higher outlet temperature of hot flow because of the high velocity and, consequently, fewer heat transfer time between cold and hot fluids in shell and tube. Therefore, since hot fluid inside the tube has not enough time, heat transfer rate is low and as a result, the fluid in tube at higher velocities has higher output temperatures than lower velocities. As the coil pitch increases, the outlet temperature of the hot flow decreases because of having more contact between hot and cold fluids which causes higher heat transfer between shell and tube fluids at high coil pitches. The variation of outlet temperature of cold fluid at various coil pitches is shown in Fig. 8.

As can be seen in Fig. 8, when fluid velocity inside tube increases, it leads to a growth in heat transfer which depends on temperature difference and flowrate, however flowrate is constant inside the shell, so temperature difference is the basic reason for heat transfer. Hence, by growing velocity in tube, outlet temperature of shell rises, and in the tube, by growing coil pitch, outlet temperature of cold fluid increases. Having more contact between hot and cold fluid flows leads to higher heat transfer rate between shell and tube at higher coil pitches. The variation of pressure drop of hot fluid at various coil pitches is displayed in Fig. 9.

In Fig. 9, pressure drop decreases as coil pitch increases because of producing more swirl flow at 

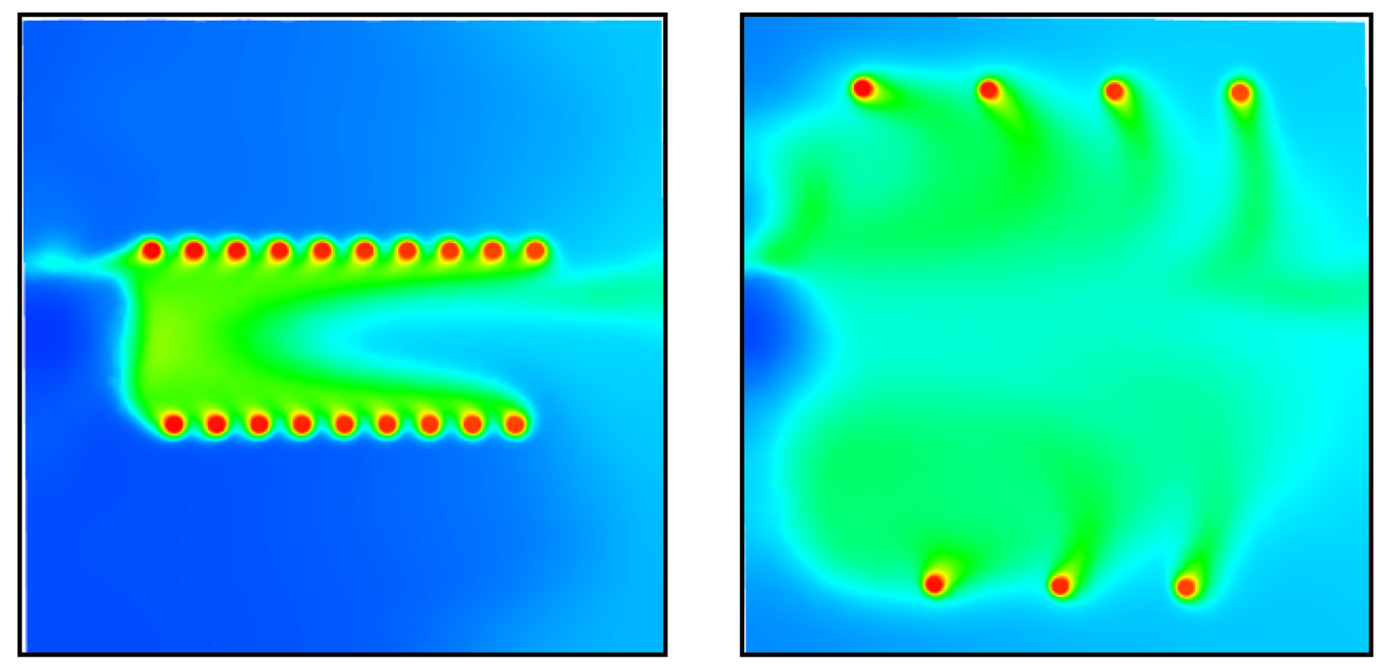

Model 1

Model 4

Temperature: $\quad 293.15296 .308299 .466302 .624305 .782308 .939312 .097315 .255318 .413321 .571$

Fig. 6 Contours of temperature in a constant Reynolds number for various coil pitches and $\mathrm{Q}=4 \mathrm{LPM}$ at $\mathrm{H}=0.36 \mathrm{~m}$ and $\mathrm{d}_{\mathrm{C}}=0.016 \mathrm{~m}$

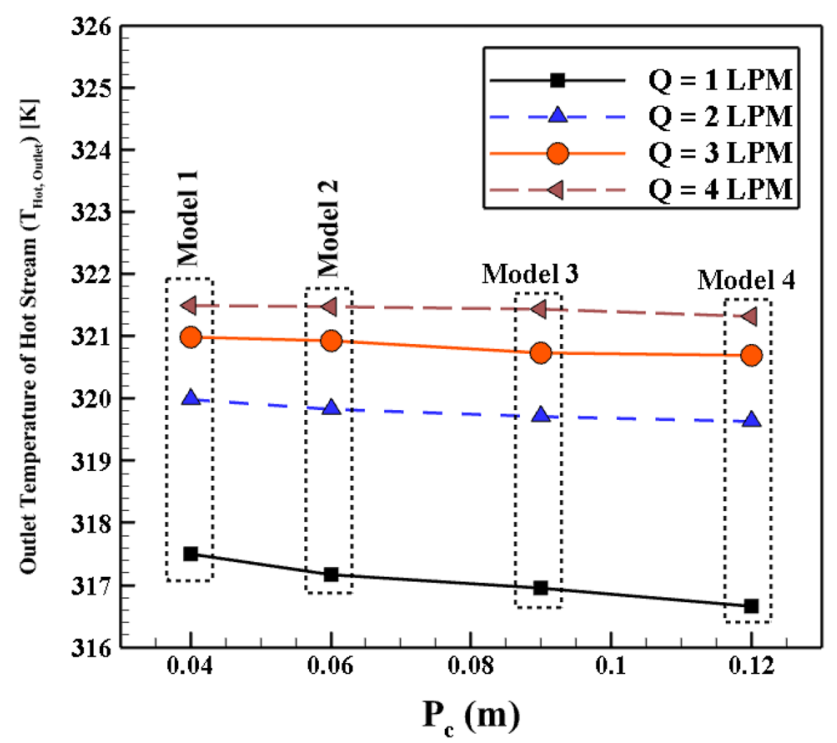

Fig. 7 Variation of outlet temperature of hot fluid for various coil pitches at $\mathrm{H}=0.36 \mathrm{~m}$ and $\mathrm{d}_{\mathrm{C}}=0.016 \mathrm{~m}$

smaller coil pitches. So, fluid passes more distances and the pressure drop increases. But pressure drop inside the shell in all models is less than 1\%. Figure 10 illustrates the change in coefficient of performance (COP) at various coil pitches. The coefficient of performance is calculated by Eq. (8). Figure 10 shows that as the coil pitch increases (model 1 to 4), the COP decreases. Model 1 has the highest COP in all Reynolds number. The results for

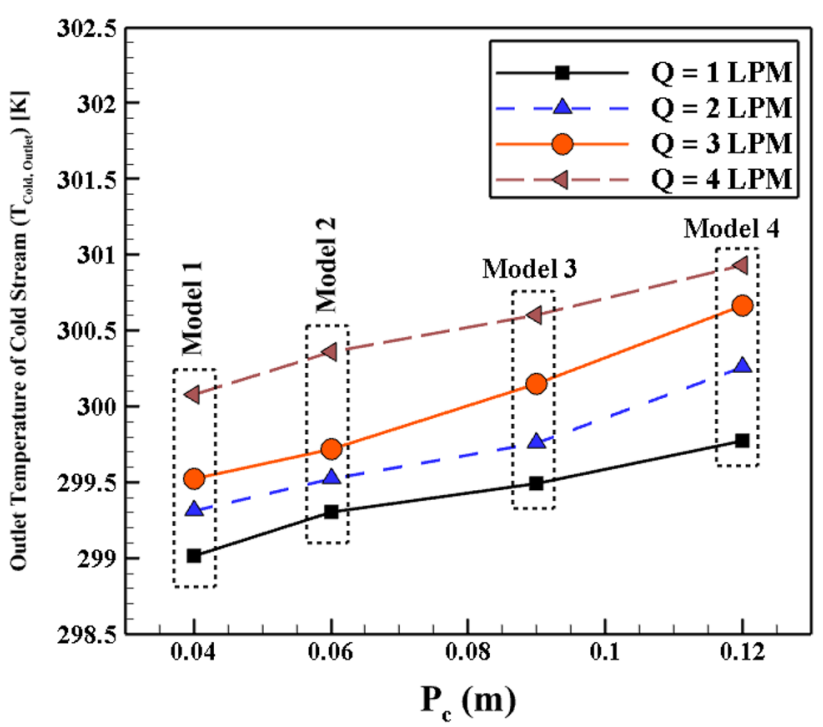

Fig. 8 Variation of outlet temperature of cold fluid for various coil pitches at $\mathrm{H}=0.36 \mathrm{~m}$ and $\mathrm{d}_{\mathrm{C}}=0.016 \mathrm{~m}$

models 3 and 4 are very close to each other. The lowest COP belongs to models 3 and 4 .

\subsubsection{Influence of Coil Internal Diameter}

In this section, the effect of coil internal diameter on heat transfer between the fluids in tube and shell is studied numerically. Four different coil internal diameter, including $0.016,0.018,0.02$, and 0.022 are considered here and 


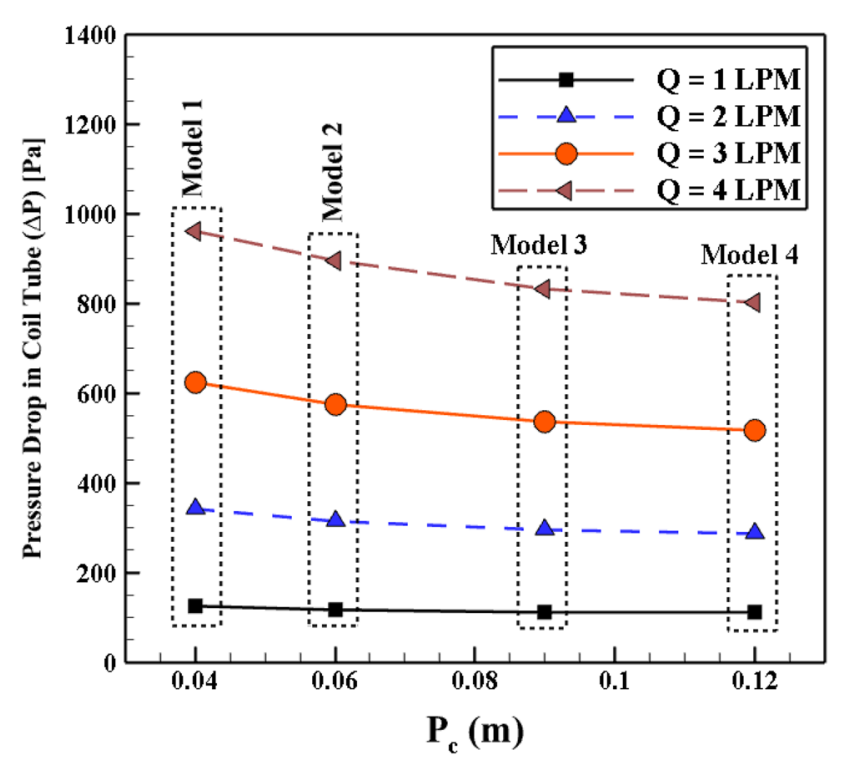

Fig. 9 Variation of pressure drop of hot fluid for various coil pitches at $\mathrm{H}=0.36 \mathrm{~m}$ and $\mathrm{d}_{\mathrm{C}}=0.016 \mathrm{~m}$

presented as models 5 to 8 . The detailed results are listed in Table 4. Here helix height $(\mathrm{H})$ and coil pitch $\left(\mathrm{P}_{\mathrm{C}}\right)$ are kept constant as $0.36 \mathrm{~m}$ and $0.09 \mathrm{~m}$, respectively. The variation of Nusselt number as well as contours of temperature at various coil diameters are demonstrated in Figs. 11 and 12. It can be seen that with the increase in coil diameter, the Nusselt number inside the tube increases. Figure 12 shows that as the coil diameter increases, to keep constant the heat transfer area here $\left(1.2 \times 10^{-3} \mathrm{~m}^{2}\right)$, the helix diameter decreases which affect the temperature distribution in the shell. On the other hand, coil with lower diameter has more effect on fluid flow and heat transfer in the shell because of covering more region of the shell.
The variation of pressure difference of hot fluid with Dean Number at various coil diameters is displayed in Fig. 13. Accordingly, by increasing coil diameter, the pressure drop decreases so that pressure drop will increase by increasing flow rate of fluid at a certain coil diameter. In Fig. 14, change in coefficient of performance at various coil diameters and Reynolds number of hot fluid flow is shown.

Figure 14 shows that as the diameter of the coil increases, the COP increase in all studied Reynolds number of hot fluid flow. Also, it should be noted that the highest COP in all studied coil diameter belongs to lowest Reynolds number of hot fluid flow $(\operatorname{Re}=1300)$. Model 8 $\left(d_{C}=0.022 \mathrm{~m}\right)$ at $\operatorname{Re}=1300$ has the highest COP.

\subsubsection{Influence of Helix Height}

In this section, the effect of helix height on heat transfer between the fluids in tube and shell is studied numerically. Four different helix height, including 240,300,360, and $420 \mathrm{~mm}$ are considered here and presented as models 9 to 12. The detailed results are listed in Table 4. Here coil pitch $\left(P_{C}\right)$ and coil diameter $\left(d_{C}\right)$ are kept constant as $0.04 \mathrm{~m}$ and $0.016 \mathrm{~m}$, respectively. Nusselt number variations as well as contours of temperature at various helix heights are shown in Figs. 15 and 16.

According to Fig. 14, as height of helix increases, Nusselt number rises. Also, at a constant helix of the height, increment of the Reynolds number leads to higher average Nusselt number. As demonstrated in Fig. 14, by decreasing the height of helix, better contact is made between fluid flow of tube and shell, so the heat transfer between two fluids improves.

Figure 16 shows that as the height of helix increases, to keep constant the heat transfer area, helix diameter declines which covering region by the coil decreases. So,
Fig. 10 Coefficient of performance (COP) versus the volume flowrate of tube for different helix pitches at $\mathrm{H}=0.36 \mathrm{~m}$ and $\mathrm{d}_{\mathrm{C}}=0.016 \mathrm{~m}$

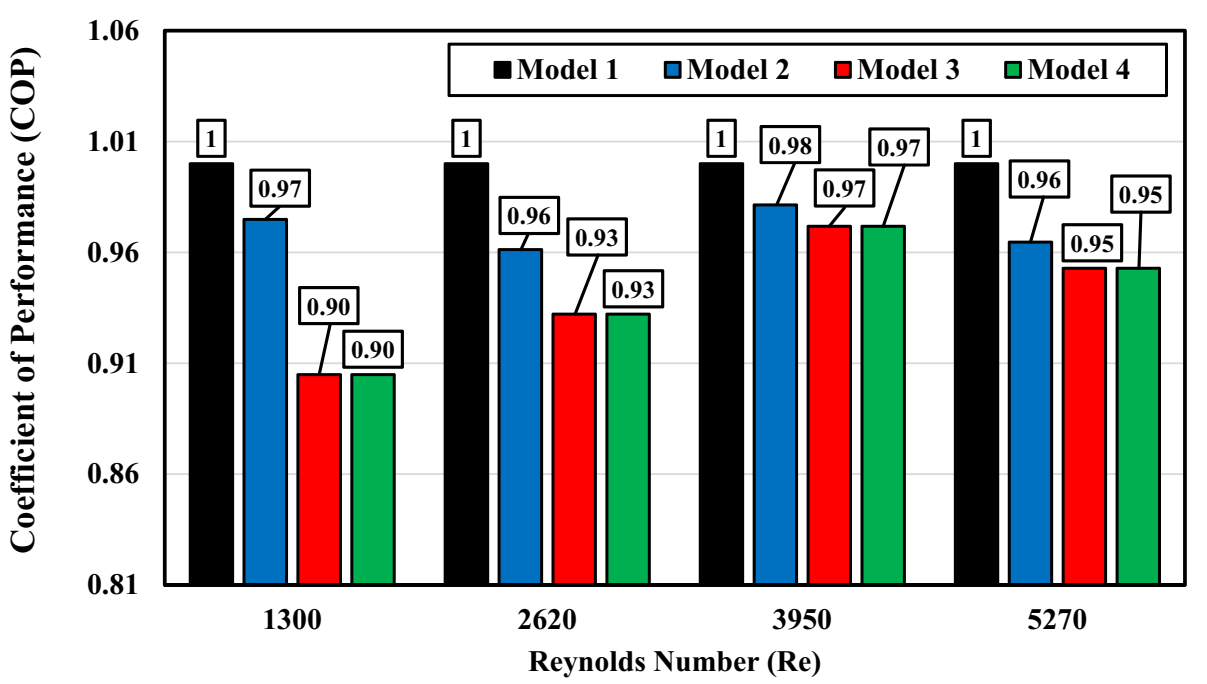




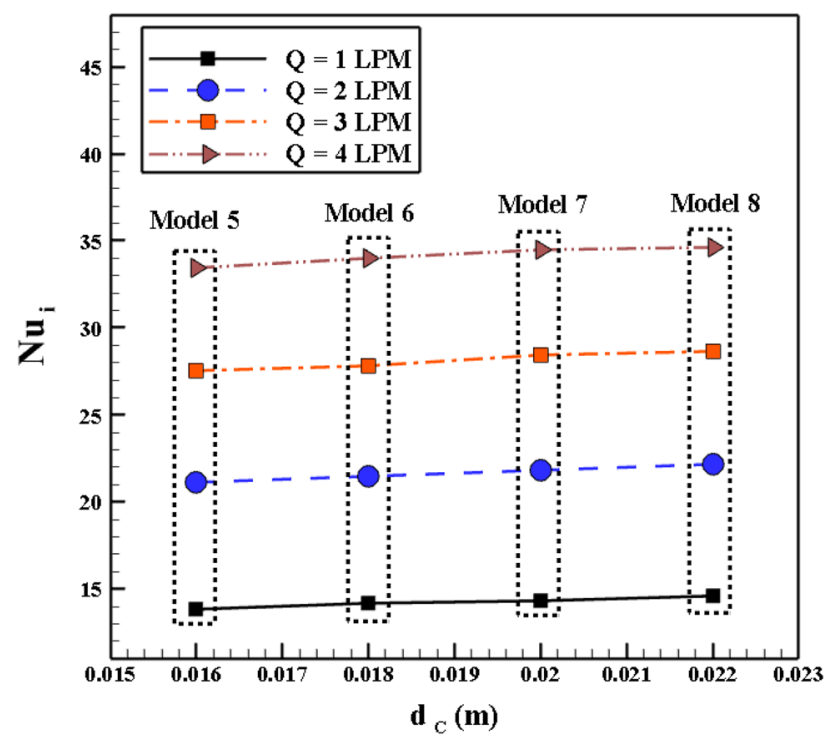

Fig. 11 Average Nusselt number versus the coil diameter for different volume flowrate of tube at $\mathrm{H}=0.36 \mathrm{~m}$ and $\mathrm{P}_{\mathrm{C}}=0.09 \mathrm{~m}$

the temperature distribution at low height of helix is better which leads to higher heat transfer rate.

Figure 17 shows the coefficient of performance (COP) versus various helix heights for different Reynolds number of coil tube. According to Table 3, from model 9 to 12, coil height $(\mathrm{H})$ increases. In Fig. 17, the base model is model 9 $(\mathrm{H}=0.24 \mathrm{~m})$ with $\mathrm{COP}=1$. So, as the coil height rises (model 9 to 12), the COP declines which the trend is the similar for whole considered Reynolds number of coil tube. Also, the highest and lowest COP belong to model $9(\mathrm{H}=0.24 \mathrm{~m})$ and model $12(\mathrm{H}=0.42 \mathrm{~m})$, respectively. For instance, at low Re number $(\operatorname{Re}=1300)$, growth of the height of coil (model 9 to 12 or $\mathrm{H}=0.24 \mathrm{~m}$ to $\mathrm{H}=0.42 \mathrm{~m}$ ) leads to decrease $14 \%$ in COP. At high Re number $(\operatorname{Re}=5270)$, by increasing the height of coil from 0.24 to $0.42 \mathrm{~m}$, the COP decreases $16 \%$.

\subsection{Utilizing nanofluid as working fluid}

The use of accurate values of fluid properties in designing a heat exchanger is important in a particular process. Especially when the fluid is complex and is also under the effect of cooling and heating processes. In fact, fluid properties that are function of temperature result in some problem in designing a heat exchanger.

\subsubsection{Effects of various water based nanofluid}

In this section, the effect of nanofluid with different volumetric factors on a fixed geometry, which is the first heat exchanger of the first model (Model 1) in this study, has been investigated. In all cases, nanofluid is in tube and shell flux is assumed to be constant. In a constant volumetric flow rate, the volumetric concentration of nanofluid is changed from 2 to $5 \%$. The $\mathrm{Al}_{2} \mathrm{O}_{3}, \mathrm{CuO}, \mathrm{SiO}_{2}$ nanofluids are chosen in this study. Thermo physical properties of considered nanofluids are presented in Table 5. The influence of flow rate at a constant volumetric concentration of nanofluids on tube heat transfer coefficient and helical coil pressure drop is shown in Fig. 18a, b.

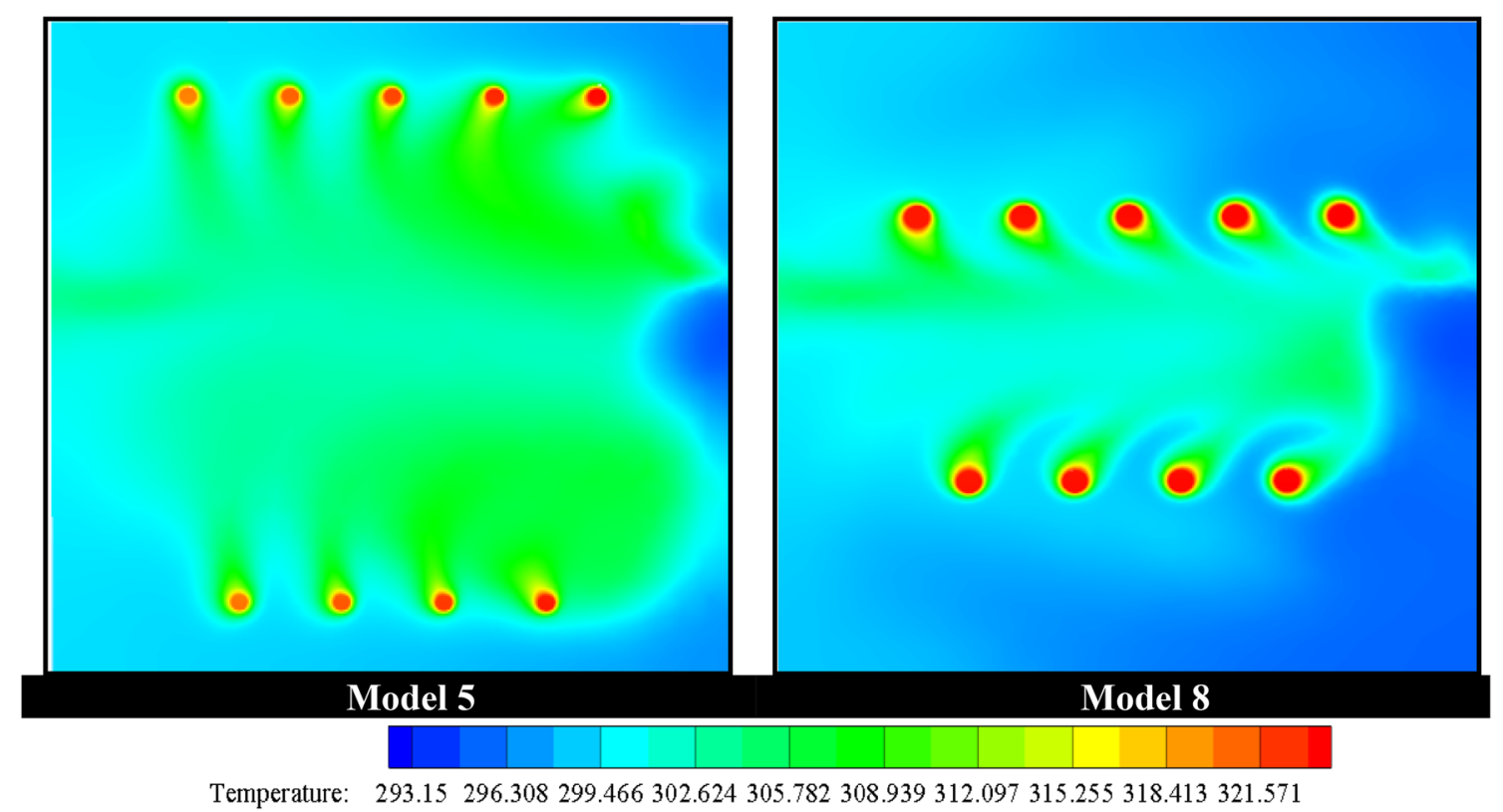

Fig. 12 Contour of temperature in a constant Reynolds number for various coil diameters and $\mathrm{Q}=4 \mathrm{LPM}$ at $\mathrm{H}=0.36 \mathrm{~m}$ and $\mathrm{P}_{\mathrm{C}}=0.09 \mathrm{~m}$ 


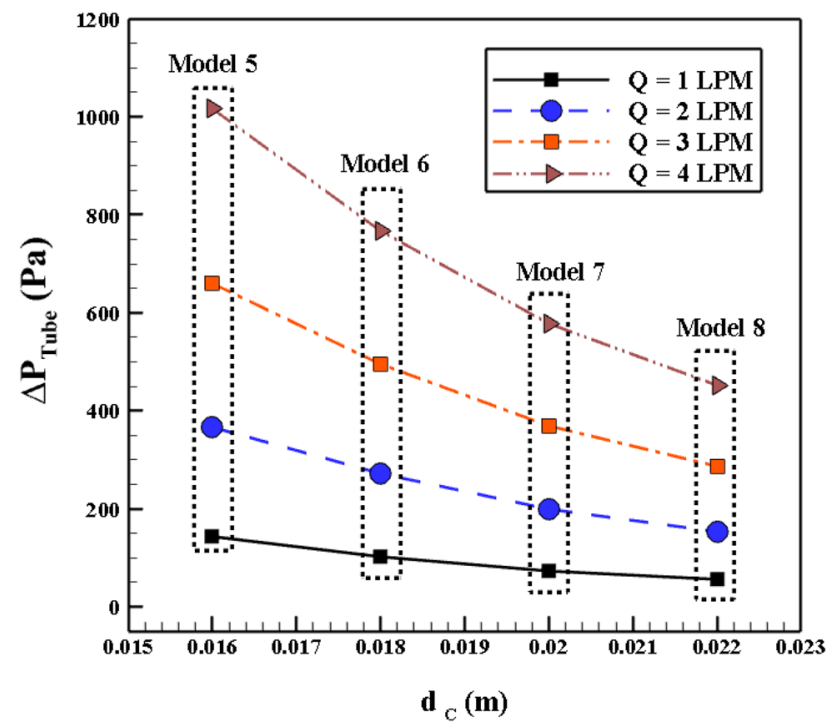

Fig. 13 Variation of pressure drop of hot fluid for various coil diameters at $\mathrm{H}=0.36 \mathrm{~m}$ and $\mathrm{P}_{\mathrm{C}}=0.09 \mathrm{~m}$

In Fig. 18a, the heat transfer coefficient of the base model is compared with three types of nanofluids with similar concentrations (2\%), and different flow rates. As is clear, the heat transfer coefficient of the tube side usually increases with the increase in the flow rate of the tube side. The reason for this is that the higher the velocity of the fluid is, the lower the difference in temperature between the fluid, and the surface of the tube will be. This is due to the presence of an additive substance, the Nano fluid particles, which is considered as passive method for heat transfer enhancement e.g., methods that do not require external power, and if necessary, additional power is supplied from available system power). Variations in pressure

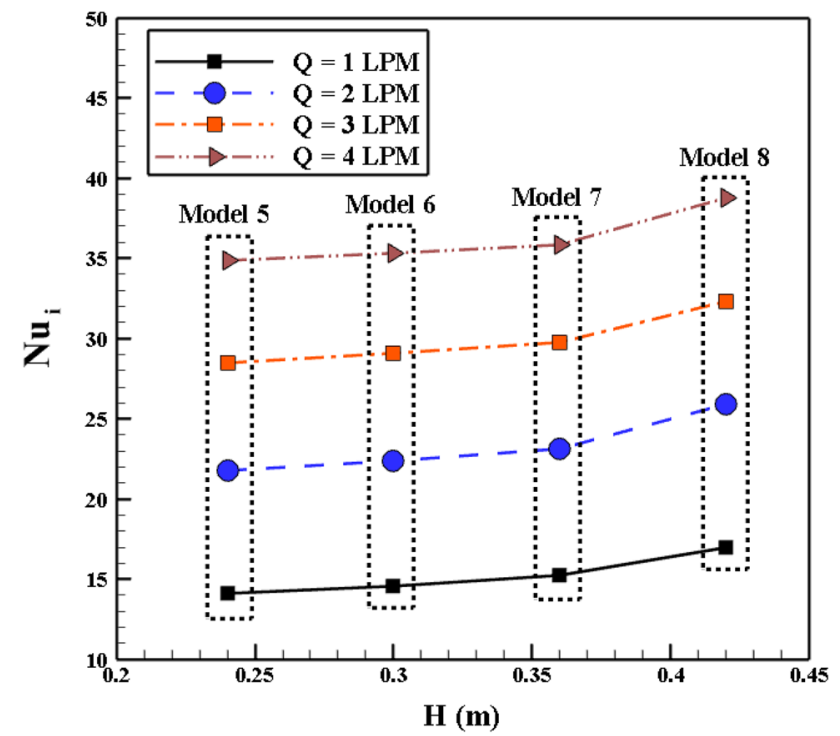

Fig. 15 Average Nusselt number versus the helix heights for different volume flowrate of tube at $d_{C}=0.16 \mathrm{~m}$ and $P_{C}=0.04 \mathrm{~m}$

drop for different flow rates of the coil is presented in Fig. 18b.

As shown in Fig. 18b, the pressure drop in the tube direction increases as the flow rate of the tube direction increases with a constant volume concentration (2\%). Moreover, pressure drop in Nano fluid $\mathrm{CuO}$ is more than $\mathrm{SiO}_{2}$, and $\mathrm{Al}_{2} \mathrm{O}_{3}$. Generally, the pressure drop in the $\mathrm{CuO}$ is higher than other models.

As it can be seen, the coefficient of performance variations based on the different Reynolds number for different nanofluids, and water are presented in Fig. 19. According to Eq. (8), the coefficient of performance equals to the division of two dimensionless quantities, and pressure
Fig. 14 Coefficient of performance (COP) versus the volume flowrate of tube for different coil diameters at $\mathrm{H}=0.36 \mathrm{~m}$ and $\mathrm{P}_{\mathrm{C}}=0.09 \mathrm{~m}$

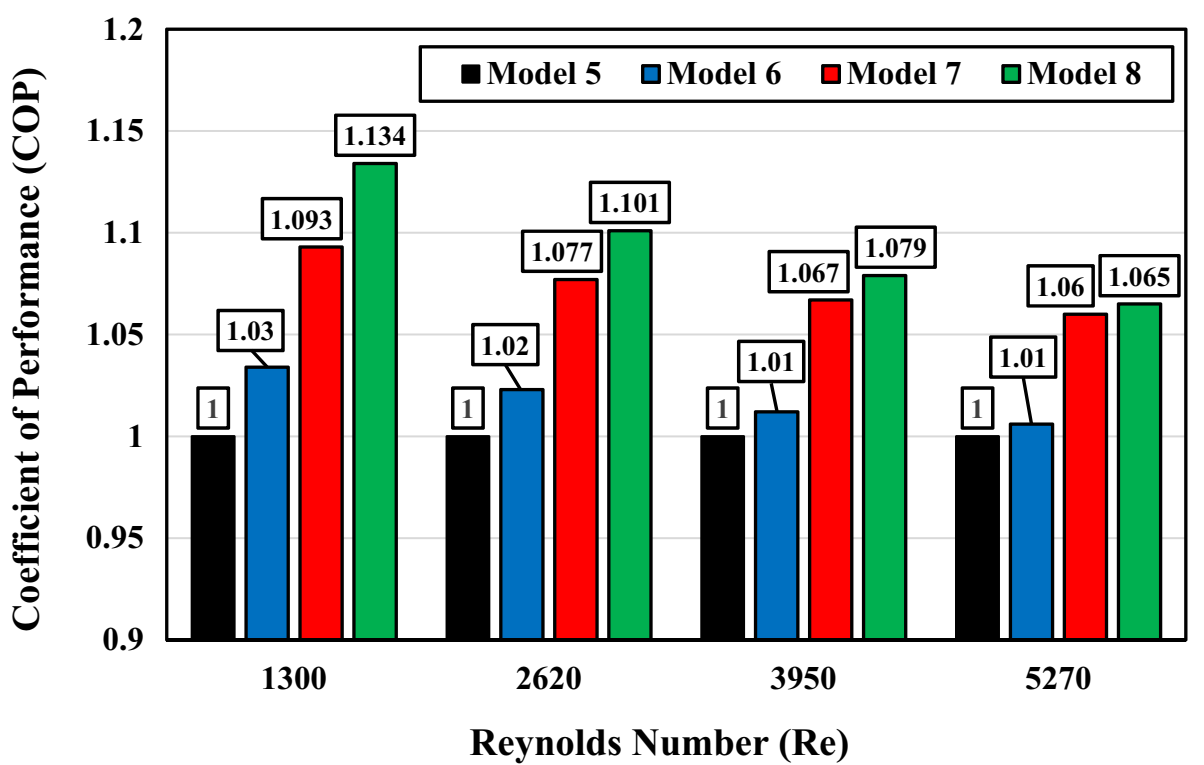




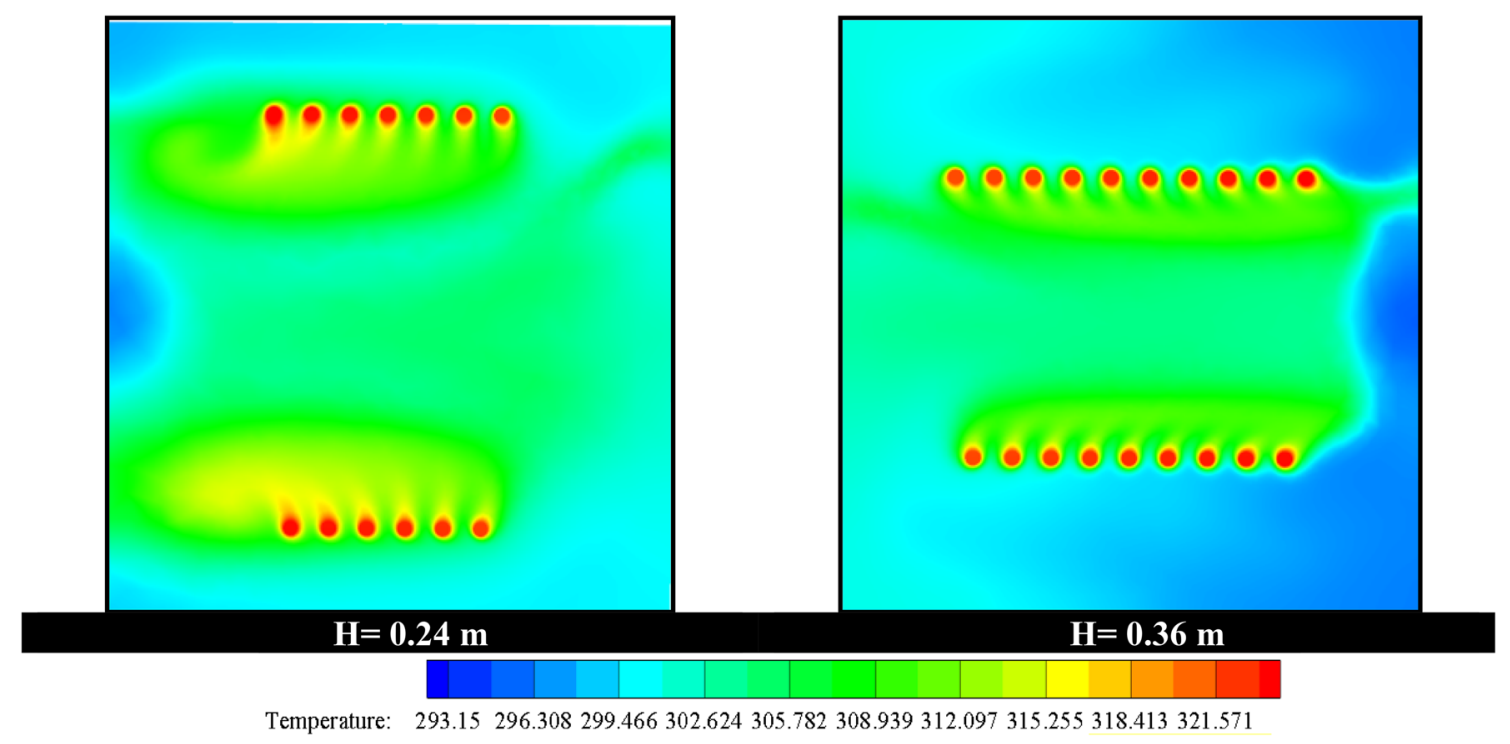

Fig. 16 Contour of temperature for two various helix heights at $Q=4 L P M$ at $d_{C}=0.16 \mathrm{~m}$ and $P_{C}=0.04 \mathrm{~m}$

Fig. 17 Coefficient of performance (COP) versus the volume flowrate of coil tube for different helix heights at $\mathrm{d}_{\mathrm{C}}=0.16 \mathrm{~m}$ and $\mathrm{P}_{\mathrm{C}}=0.04 \mathrm{~m}$

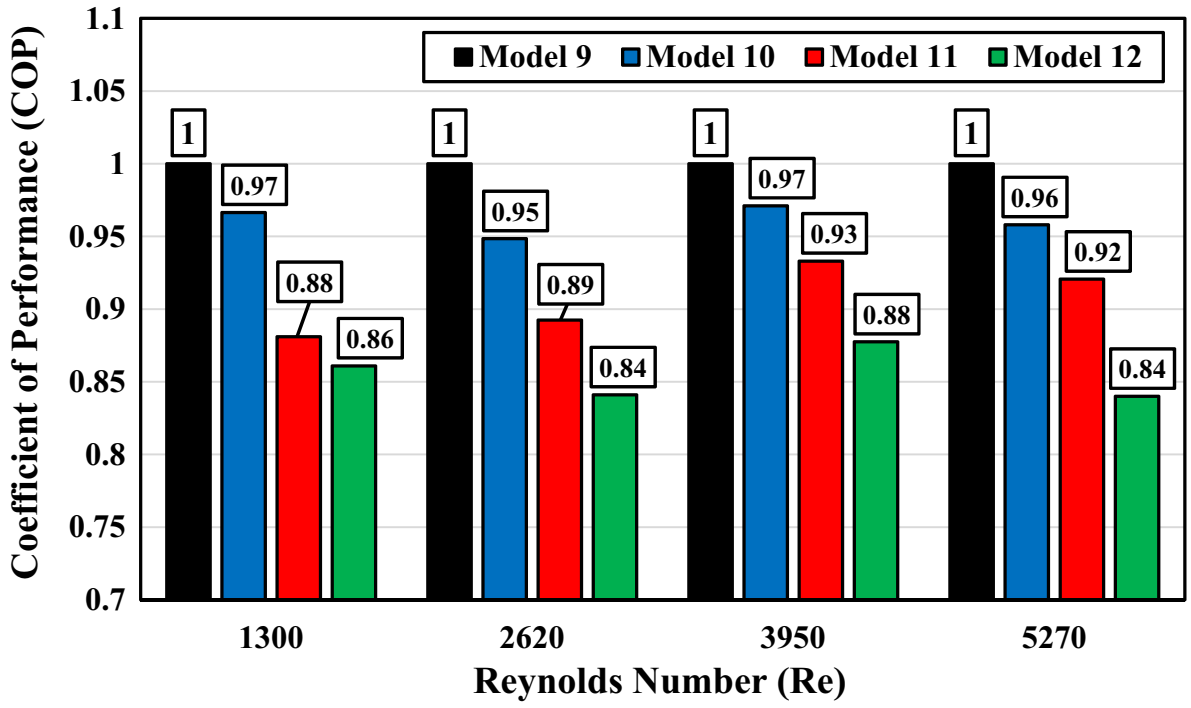

drop. According to Fig. 18, the highest coefficient of performance is created for the heat exchanger with $\mathrm{CuO}$, and the third Reynolds number. That is, it has the highest heat transfer coefficient ratio, and the lowest pressure drop. This has led to this model being chosen as the best decision among other nanofluids.

\subsubsection{Effect of volume concentration of water-based nanofluids}

As mentioned in the previous section, the best choice between heat exchangers with nanofilms was nanofluid $\mathrm{CuO}$. In this section, the basic fluid as well as other different nanowires with different concentrations in the heat exchanger are examined.

Of these, the helical tube, and shell with Nano fluids $\mathrm{CuO}$ has the highest coefficient of performance. In this section, the CuO Nano fluid in a five-lobe shell, and helically corrugated tube heat exchanger is examined at different concentrations (from 2 to $5 \%$ ) with a constant Reynolds number (the last one) to select the best mode. Table 6 provides the properties of $\mathrm{CuO}$ in different concentrations. The influence of volumetric concentration of nanofluids on tube heat transfer coefficient and helical coil pressure drop are shown in Fig. 20a, b, respectively.

By proliferating the volume concentration of the nanofluids, the heat transfer coefficient on the helical tube side 
Table 5 Thermophysical properties of studied nanofluid

\begin{tabular}{lll}
\hline Fluid & $\begin{array}{l}\text { Nanosilicon con- } \\
\text { centration }\end{array}$ & $\begin{array}{l}\text { Thermal conductivity coef- } \\
\text { ficient }(\mathrm{W} / \mathrm{m} \mathrm{K})\end{array}$
\end{tabular}

Specific heat capacity $(\mathrm{J} /$ $\mathrm{Kg} \mathrm{K})$

\begin{tabular}{lllll}
\hline $\mathrm{AL}_{2} \mathrm{O}_{3}$ & 2 & 36 & 1050.236 & 3947.74 \\
$\mathrm{CuO}$ & 2 & 17.65 & 1108.236 & 3753.95 \\
$\mathrm{SiO}_{2}$ & 2 & 1.4 & 1022.636 & 4032.77 \\
Water & - & 0.6 & 998 & 4180 \\
\hline
\end{tabular}

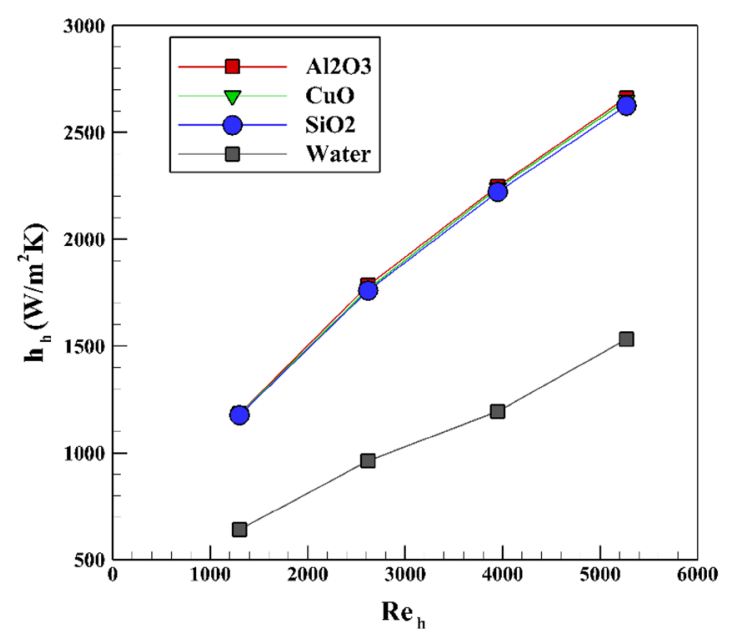

(a)

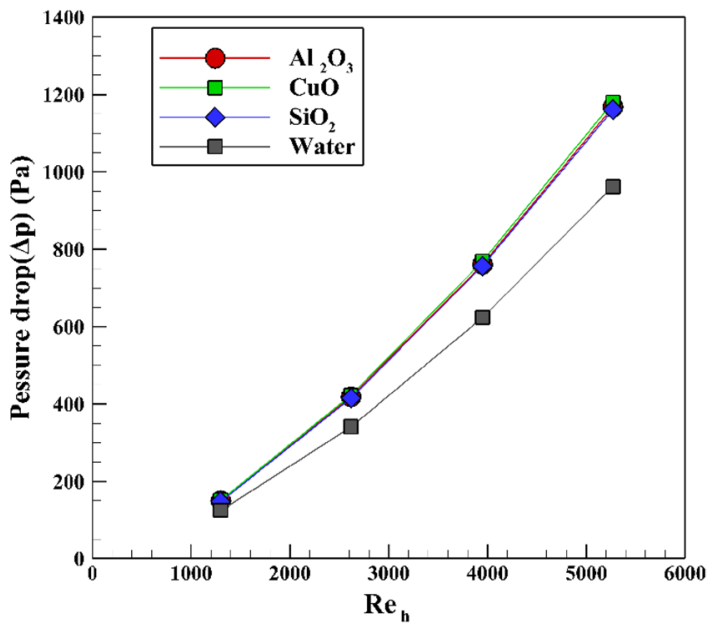

(b)

Fig. 18 (a) Heat transfer coefficient (h) versus Reynolds number of corrugated tube (hot fluid flow) for various water-based nanofluid. (b) Pressure drop versus Reynolds number of corrugated tube (hot fluid flow) for various water-based nanofluid

Fig. 19 Coefficient of performance (COP) versus Reynolds number of corrugated tube (hot fluid flow) for various water-based nanofluid

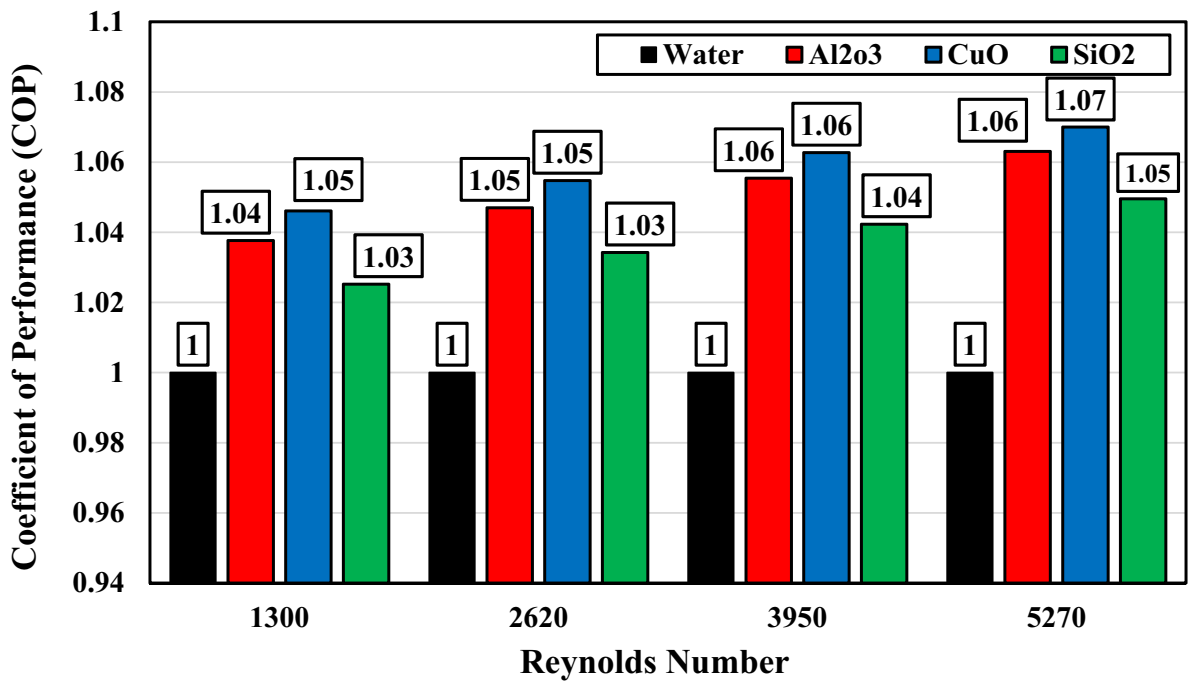

increases, as is shown in Fig. 20a. In numerical calculations, the heat transfer coefficient expressed as a percentage of the nanofluid concentration is usually expressed as upward or downward. However, in experimental experiments, the heat transfer coefficient does not always increase with increasing concentrations. The reason is that in case of excessive increase in nanofluids, the effect of the heat transfer enhancement may be reduced or even 
Table 6 Thermos-physical properties of $\mathrm{CuO}[27,28]$

\begin{tabular}{llllll}
\hline Fluid & $\begin{array}{l}\text { Nanosilicon } \\
\text { concentration }\end{array}$ & $\begin{array}{l}\text { Diameter of nano- } \\
\text { particles }(\mathrm{dpp})(\mathrm{nm})\end{array}$ & $\begin{array}{l}\text { Thermal conductivity } \\
\text { coefficient }(\mathrm{W} / \mathrm{m} \mathrm{K})\end{array}$ & Density $\left(\mathrm{kg} / \mathrm{m}^{3}\right)$ & $\begin{array}{l}\text { Specific heat } \\
\text { capacity }(\mathrm{J} / \\
\mathrm{Kg} \mathrm{K})\end{array}$ \\
\hline $\mathrm{CuO}$ & 2 & 29 & 17.65 & 1108.236 & 3753.95 \\
& 3 & 29 & 17.65 & 1163.254 & 3570.30 \\
4 & 29 & 17.65 & 1218.272 & 3403.24 \\
& 29 & 17.65 & 1273.290 & 3250.61 \\
\hline
\end{tabular}

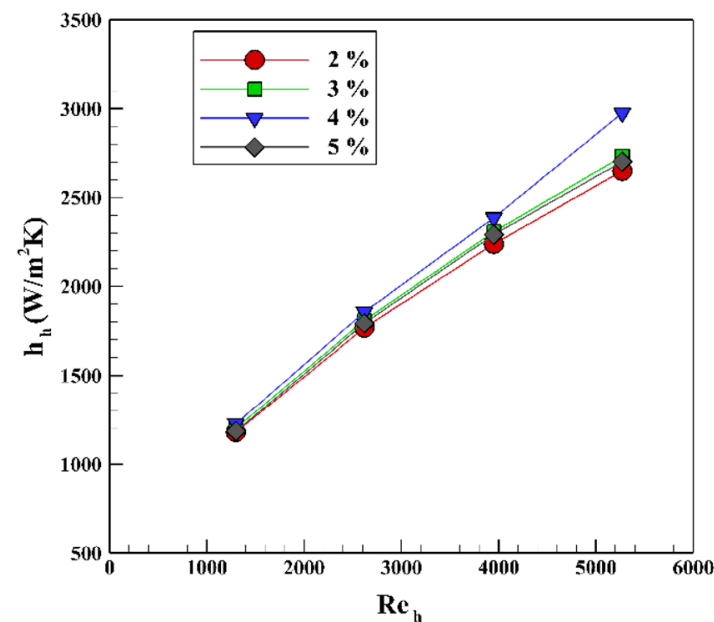

(a)

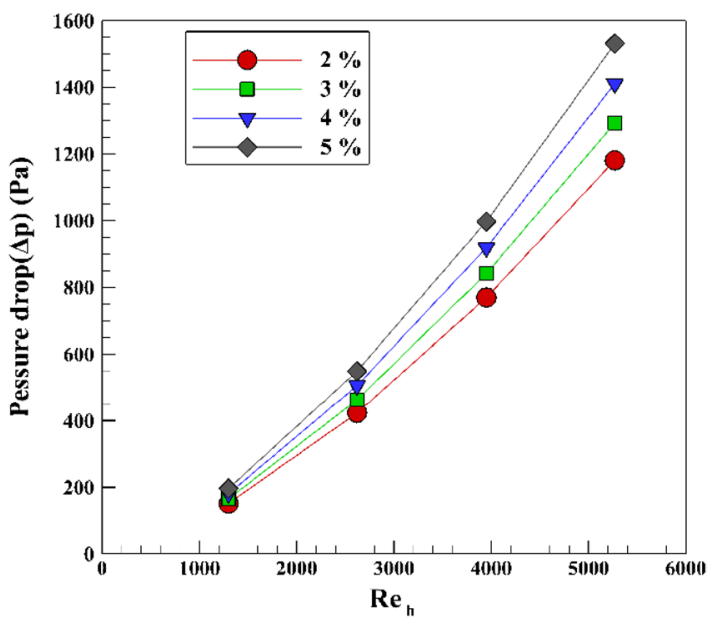

(b)

Fig. 20 Heat transfer coefficient (h) and pressure drop versus various volume concentration of the Cuo

Fig. 21 Coefficient of performance (COP) versus various volume concentration of the Cuo/water nanofluid

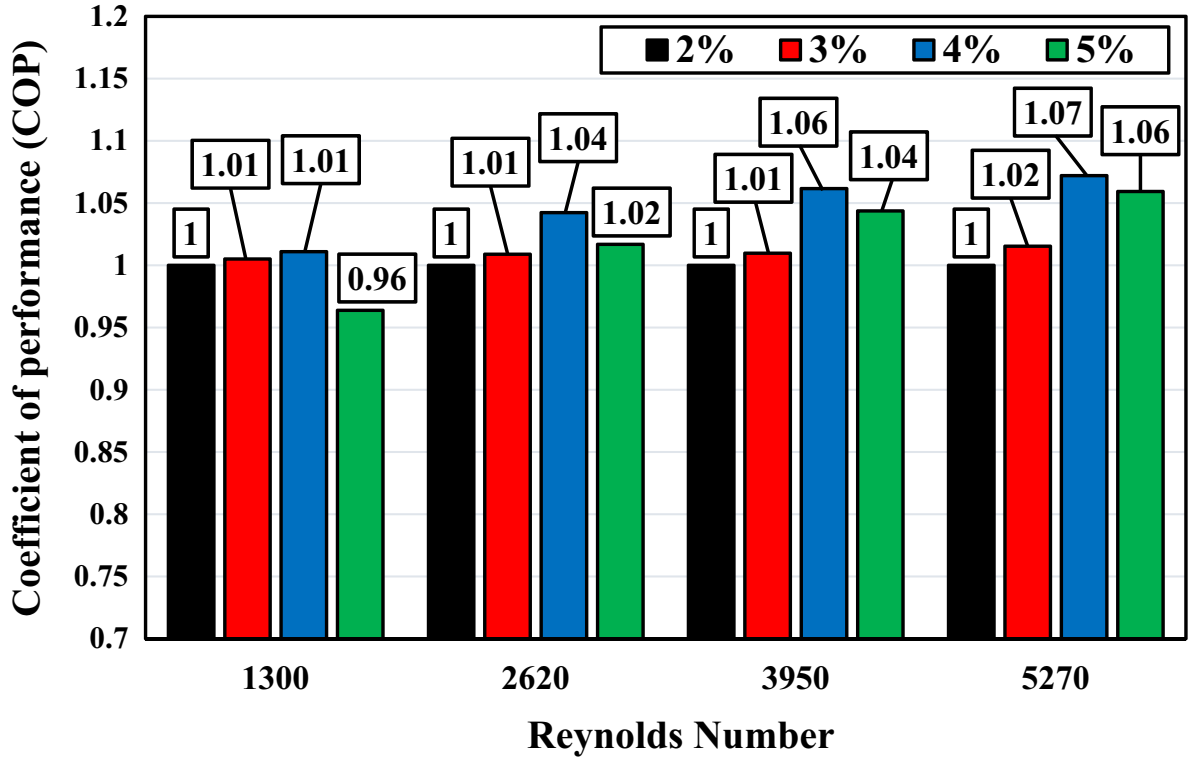

The coefficient of performance (COP) of the considered heat exchanger with $\mathrm{CuO}$ nanofluid in the coil and water in the shell are illustrated in Fig. 21. Four different centrations. It is shown in Fig. $20 \mathrm{~b}$ that by increasing the volume concentration of nanofluid, the pressure drop of fluid in coil tube rises. 
volume concentration of the nanofluid including 2, 3, 4, and $5 \%$ are considered here. Accordingly, it can be seen that, in all investigated Reynolds number, the maximum COP belongs to $\phi=4 \%$. Also, except the low Re number $(\operatorname{Re}=1300)$, the cases with $\phi=4$ and $5 \%$ are the first and second levels. As a results, the maximum and minimum COP belong to $\phi=4 \%(\operatorname{Re}=5270)$ and $\phi=5 \%(\operatorname{Re}=1300)$, respectively.

\section{Conclusions}

The objective of this study is to investigate efficient operational and geometrical parameters of fluid flow in a shell and coil tube heat exchanger. The considered geometrical parameters include helix pitch, coil diameter, and helix height. Also, the effect of using $\mathrm{Al}_{2} \mathrm{O}_{3}, \mathrm{CuO}, \mathrm{SiO}_{2}$ nanofluids on thermal performance of the heat exchanger is investigated numerically. The obtained results are as follows:

- By increasing helix pitch $50 \%$ (0.04 to $0.12 \mathrm{~m}$ ), outlet temperature of hot fluid, pressure drop of flow inside tube and temperature difference of hot fluid reduce by less than $1 \%, 1 \%$ and $5 \%$, respectively. Also, outlet temperature of cold fluid and temperature difference of cold fluid increase by less than $1 \%$ and $5 \%$, respectively.

- By increasing helix diameter $11 \%$ (0.016 to 0.022 ), outlet temperature of hot fluid and temperature difference of cold fluid increase by less than $1 \%$ and $8 \%$, respectively. Also, outlet temperature of cold fluid, pressure drop of flow inside tube and temperature difference of hot fluid reduce by less than $1 \%, 37 \%$ and $8 \%$, respectively.

- By increasing helix height $25 \%$ (0.24 to $0.36 \mathrm{~m}$ ), outlet temperature and temperature difference of hot fluid reduce by less than $1 \%$ and $8 \%$, respectively. Also, outlet temperature and temperature difference of cold fluid increase by less than $1 \%$ and $8 \%$.

- Between the considered water based nanofluid, the highest coefficient of performance belongs to water/ $\mathrm{CuO}$ nanofluid at $\mathrm{Re}=3950$.

- Heat transfer coefficient in tube does not change considerably with increase in volumetric concentration of nanofluid. The lowest and highest coefficient coefficient are obtained for $2 \%$ and $4 \%$ volume concentration of nanofluid, respectively.

\section{Compliance with ethical standards}

Conflict of interest The authors declare no conflict of interest.

\section{References}

1. Kumar V, Saini S, Sharma M, Nigam KDP (2006) Pressure drop and heat transfer study in tube-in-tube helical heat exchanger. Chem Eng Sci 61(13):4403-4416

2. Salimpour MR (2009) Heat transfer coefficients of shell and coiled tube heat exchangers. Exp Therm Fluid Sci 33(2):203-207

3. Salimpour MR (2008) Heat transfer characteristics of a temperature-dependent-property fluid in shell and coiled tube heat exchangers. Int Commun Heat Mass Transf 35(9):1190-1195

4. Dravid AN, Smith KA, Merrill EW, Brian PLT (1971) Effect of secondary fluid motion on laminar flow heat transfer in helically coiled tubes. AIChE J 17(5):1114-1122

5. Jayakumar JS, Mahajani SM, Mandal JC, Iyer KN, Vijayan PK (2010) CFD analysis of single-phase flows inside helically coiled tubes. Comput Chem Eng 34(4):430-446

6. Jayakumar JS, Mahajani SM, Mandal JC, Vijayan PK, Bhoi R (2008) Experimental and CFD estimation of heat transfer in helically coiled heat exchangers. Chem Eng Res Des 86(3):221-232

7. Hashemi SM, Akhavan-Behabadi MA (2012) An empirical study on heat transfer and pressure drop characteristics of $\mathrm{CuO}$-base oil nanofluid flow in a horizontal helically coiled tube under constant heat flux. Int Commun Heat Mass Transf 39(1):144-151

8. Choi SU, Eastman JA (1995) Enhancing thermal conductivity of fluids with nanoparticles (No. ANL/MSD/CP-84938; CONF951135-29). Argonne National Laboratory, IL (United States), 1995

9. Sheikholeslami M, Mahian O (2019) Enhancement of PCM solidification using inorganic nanoparticles and an external magnetic field with application in energy storage systems. J Clean Prod 215:963-977

10. Sheikholeslami M (2018) Solidification of NEPCM under the effect of magnetic field in a porous thermal energy storage enclosure using CuO nanoparticles. J Mol Liq 263:303-315

11. Sheikholeslami Mohsen (2018) Numerical simulation for solidification in a LHTESS by means of Nano-enhanced PCM. J Taiwan Inst Chem Eng 86:25-41

12. Hardik BK, Baburajan PK, Prabhu SV (2015) Local heat transfer coefficient in helical coils with single phase flow. Int J Heat Mass Transf 89:522-538

13. Murshed SMS, Leong KC, Yang C (2005) Enhanced thermal conductivity of $\mathrm{TiO}_{2}$ - water based nanofluids. Int J Therm Sci 44(4):367-373

14. Wen D, Ding Y (2004) Experimental investigation into convective heat transfer of nanofluids at the entrance region under laminar flow conditions. Int $J$ Heat Mass Transf 47(24):5181-5188

15. Yang G, Ebadian MA (1996) Turbulent forced convection in a helicoidal pipe with substantial pitch. Int J Heat Mass Transf 39(10):2015-2022

16. Sheikholeslami Mohsen (2017) Magnetic field influence on $\mathrm{CuO}-\mathrm{H}_{2} \mathrm{O}$ nanofluid convective flow in a permeable cavity considering various shapes for nanoparticles. Int J Hydrog Energy 42:19611-19621

17. Sheikholeslami M (2018) Finite element method for PCM solidification in existence of CuO nanoparticles. J Mol Liq 265:347-355

18. Austen DS, Soliman HM (1988) Laminar flow and heat transfer in helically coiled tubes with substantial pitch. Exp Therm Fluid Sci 1(2):183-194 
19. Jamshidi N, Farhadi M, Ganji DD, Sedighi K (2013) Experimental analysis of heat transfer enhancement in shell and helical tube heat exchangers. Appl Therm Eng 51(1-2):644-652

20. Andrzejczyk R, Muszynski T (2017) Thermodynamic and geometrical characteristics of mixed convection heat transfer in the shell and coil tube heat exchanger with baffles. Appl Therm Eng 121:115-125

21. Hameed VM, Al-Khafaji AR (2017) Experimental and numerical investigation of temperature distribution through shell and helical coil tube heat exchanger using Lab VIEW as a data acquisition program. Part II: parametric investigation. Energy Environ $8: 253-270$

22. Naik BAK, Vinod AV (2018) Heat transfer enhancement using non-Newtonian nanofluids in a shell and helical coil heat exchanger. Exp Therm Fluid Sci 90:132-142

23. Sheikholeslami $M$ (2018) Influence of magnetic field on $\mathrm{Al}_{2} \mathrm{O}_{3}-\mathrm{H} 2 \mathrm{O}$ nanofluid forced convection heat transfer in a porous lid driven cavity with hot sphere obstacle by means of LBM. J Mol Liq 263:472-488

24. Sheikholeslami M (2019) Numerical approach for MHD $\mathrm{Al}_{2} \mathrm{O}_{3}$-water nanofluid transportation inside a permeable medium using innovative computer method. Comput Methods Appl Mech Eng 344:306-318

25. Zare M, Heyhat MM (2019) Performance evaluation of nanofluid flow in conical and helical coiled tubes. Therm Anal Calorim 135:1351-1362

26. Mohapatra T, Padhi BN, Sahoo SS (2019) Analytical investigation and performance optimization of a three fluid heat exchanger with helical coil insertion for simultaneous space heating and water heating. Heat Mass Transf 55:1723-1740

27. Bejan A (2013) Convective heat transfer, 4th edn. Wiley, New York

28. Fluent AN (2017) 18.2, theory guide. ANSYS Inc., Canonsburg

29. Baragh S, Shokouhmand H, Ajarostaghi SS, Nikian M (2018) An experimental investigation on forced convection heat transfer of single-phase flow in a channel with different arrangements of porous media. Int J Therm Sci 1(134):370-379

30. Shirzad M, Ajarostaghi SS, Delavar MA, Sedighi K (2019) Improve the thermal performance of the pillow plate heat exchanger by using nanofluid: numerical simulation. Adv Powder Technol 30(7):1356-1365
31. Baragh S, Shokouhmand H, Ajarostaghi SS (2019) Experiments on mist flow and heat transfer in a tube fitted with porous media. Int J Therm Sci 1(137):388-398

32. Shirzad M, Delavar MA, Ajarostaghi SSM, Sedighi K (2019) Evaluation the effects of geometrical parameters on the performance of pillow plate heat exchanger. Chem Eng Res Des 150:47-83

33. Noorbakhsh M, Zaboli M, Ajarostaghi SSM (2019) Numerical evaluation the effect of using twisted tapes as turbulator with various geometries in both sides of a double pipe heat exchanger. Int J Therm Anal Calorim. https://doi.org/10.1007/ s10973-019-08509-w

34. Hamedani FA, Ajarostaghi SSM, Hosseini SA (2019) Numerical evaluation of the effect of geometrical and operational parameters on thermal performance of nanofluid flow in convergent-divergent tube. Int J Therm Anal Calorim. https://doi. org/10.1007/s10973-019-08765-w

35. Sheikholeslami M (2018) Numerical modeling of Nano enhanced PCM solidification in an enclosure with metallic fin. J Mol Liq 259:424-438

36. Huminic G, Huminic A (2012) Application of nanofluids in heat exchangers: a review. Renew Sustain Energy Rev 16:5625-5638

37. Vajjha Ravikanth S, Das Debendra K, Kulkarni Devdatta P (2010) Development of new correlations for convective heat transfer and friction factor in turbulent regime for nanofluids. Int J Heat Mass Transf 53:4607-4618

38. Sheikholeslami M, Ghasemi A (2018) Solidification heat transfer of nanofluid in existence of thermal radiation by means of FEM. Int J Heat Mass Transf 123:418-431

39. Sheikholeslami M (2019) New computational approach for exergy and entropy analysis of nanofluid under the impact of Lorentz force through a porous media. Comput Methods Appl Mech Eng 344:319-333

40. Schmidt EF (1967) Wärmeübergang und druckverlust in rohrschlangen. Chem Ing Tech 39(13):781-789

Publisher's Note Springer Nature remains neutral with regard to jurisdictional claims in published maps and institutional affiliations. 